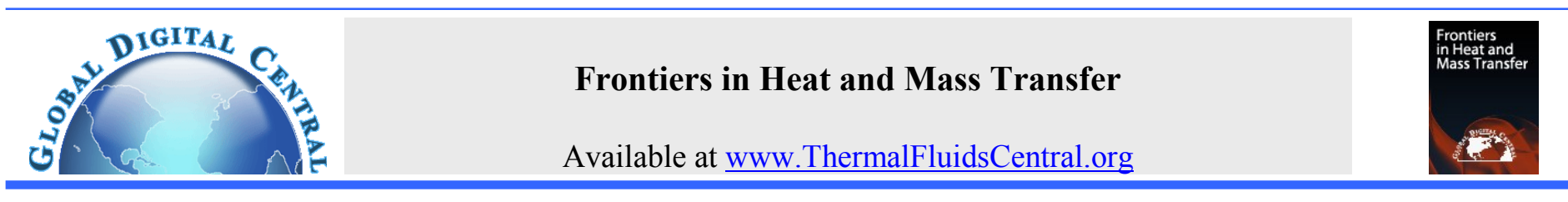

\title{
NATURAL CONVECTION IN A SQUARE ENCLOSURE WITH DIFFERENT OPENINGS AND INVOLVES TWO CYLINDERS: A NUMERICAL APPROACH
}

\author{
Mahmud H. Ali ${ }^{\text {a,**}}$, Rawand E. Jalal ${ }^{\mathrm{a}}$ \\ ${ }^{a}$ Department of Mechanical Engineering, University of Kirkuk, Kirkuk, Iraq
}

\begin{abstract}
In this work, natural convection in an adiabatic enclosure with openings induced by two isothermal hot cylinders is approached numerically. The study covers five different configurations of the enclosure as the number and locations of the inlet and outlet ports are varied for Rayleigh number (Ra) between $10^{4}$ and $10^{6}$. Additionally, the study also analyzes the effects of varying the horizontal distance (S) between the cylinders along with their vertical locations $(\delta)$ for dimensionless values of 0.4 to 0.3 and -0.2 to 0.2 , respectively, at a constant Ra of $10^{6}$. The outcomes show that the locations of the openings have a significant influence on the amount of the heat being transferred. When both $\delta$ and $\mathrm{S}$ are kept unchanged, and at low $\mathrm{Ra}$, where conduction is the main reason for heat transfer, configurations with two facing inlets illustrate low heat transfer up to $\mathrm{Ra}=2.5 \times 10^{5}$ which is reversed as $\mathrm{Ra}$ increases. However, for changes in $\mathrm{S}$ at $\mathrm{Ra}=10^{6}$, when the heat is mainly being dissipated by convection, these configurations are not only dissipating more heat rates but also show low sensitivity to increase in S. Low sensitivity for changes in $\delta$ has also been observed for the configuration with two facing outlets and one inlet. In overall, in all considered configurations, the average Nusselt number varies inversely with variation in $\delta$. Similar change is observed for configurations that have one inlet as well with variation in S. The configuration with symmetrically distributed ports shows distinguished results in heat dissipation characteristics.
\end{abstract}

Keywords: Cavity with openings, Natural convection, Isothermal cylinders, Numerical analysis.

\section{INTRODUCTION}

Natural convection is a heat transfer mechanism that occurs as a result of temperature differences between fluids and surfaces without exciting the working fluid by an external element. In past decades, efforts were employed toward investigation of natural conversion in closed cavities. This can be seen in many engineering fields as heat exchanging devices, space heating, energy storage systems, solar systems, and cooling of electronic equipment (Moukalled and Acharya 1996).

In recent years, however, substantial researches have been conducted considering cavities with full or partial openings due to large industrial applications. Some interesting examples are open cavity solar thermal receivers, heat exchanger with extended surfaces, and heat convection in rooms and thermal design of ventilation of buildings (Gowda et al. 2019). Fluid motion is motivated by the presence of heating sources or elements in the enclosure and because of ventilation openings, the fluid can travel into and from the cavity. This can produce a complicated flow patterns which affect the heat transfer characteristics. This phenomenon has received the attention of researchers where significant experimental and numerical investigations are proposed. Natural convection is studied intensively as it is a preferred method in equipment cooling where control systems such as fans or pumps can be easily avoided providing cost savings in both initial installation and later in maintenance.

Utilizing mainly numerical approaches, natural convection in closed cavities with one cylinder has investigated by [Moukalled and Acharya (1996); Roychowdhury et al. ( 2002); Shu and Zhu (2002); Hussain and Hussein (2010); Kim et al. (2014); Park et al. (2018)] and with two cylinders by [Ali (2008); park(2012); Yoon et al. (2012); Yoon et al. (2014); Karimi et al (2014); Abdi and Rezazada (2016)] under variations in many variables such as diameters and locations of the cylinder, boundary conditions of the cylinder and enclosure as well as Rayleigh numbers ( $\mathrm{Ra}$ ). In addition, natural convection under different situations employing partially opened cavities as the main configuration is also covered in literature. Numerical investigation was used by Bilgen and Muftuoglu (2008) to address natural convection in an enclosure that has openings on one side of the wall. A constant heat flux is imposed on a side-wall while the openings placed in the facing wall. In a different work, Bilgen and Balkaya (2008) considered the same geometry but used discrete heaters with constant heat flux on one wall. In these works, the effects of opening sizes and positions, number of slots in the wall and Rayleigh number were also analyzed. In a different direction, Mariani and Silva (2007) numerically examined the natural convection in a partially opened cavity containing uniform heat source. The effects of positions of the heat source and enclosure aspect ratio as well as Rayleigh numbers on the local and average Nusselt number were investigated. Fontana et al. (2011) studied the natural convection in a partially open cavity with an internal heat source placed at the center of bottom wall. The effect of opening mass flow was analyzed in a cavity for three opening sizes and different values of the Rayleigh number. The outcomes showed that the position of the opening has a significant influence on the flow pattern and heat transfer amount in the cavity. Achieving the same investigation goal, Abhenav et al. (2013) also studied partial open cavities but with an internal heat source that has different dimensions. The study involved the effect of vent locations as well at Rayleigh number from $10^{3}$ to $10^{5}$. It was illustrated that Nusselt number and mass flow rate increase with the increase in the Ra or decrease in the heat source aspect ratio.

When forced convection presents in the cavity along with natural convection, a mixed convection is produced. Obstacles can also be placed inside enclosures which affect the flow pattern and the heat

\footnotetext{
*Corresponding author, E-mail: mahmoud75@uokirkuk.edu.iq
} 
transfer characteristics may change as a result. For the configurations that are considered in this work, many researchers have considered relevant configurations with various obstacles but for mixed convection. Shuja et al. (2000) investigated mixed convection in vented enclosure with a heat generation rectangular body using numerical approach. They studied the effects of aspect ratio of the heat generating body and exit port locations on the characteristic of heat transfer and irreversibility generation. Mixed convection with heat conducting square blocks inside a vented square cavity was addressed by Rahman et al. (2008a) and Chamkha et al. (2011). The effect of geometric size, thermal conductivity, location of the block within the enclosure and location of the ventilation ports, as well as the effect of Richardson (Ri) and Reynolds (Re) numbers were all examined. In a related work, Rahman et al. (2008b) and Rahman et al (2013) also scrutinized mixed convection in vented square cavity but with a solid circular cylinder instead. They investigated the effect of the cylinder diameter, solid to fluid thermal conductivity ratio as well as the Richardson number on heat transfer and flow characteristic. The same investigations were repeated with a heated hollow cylinder by Mamun et al. (2010). Boulahia et al. (2018) have also analyzed the mixed convection in cavities containing circular cooling obstacle where $\mathrm{Cu}$-water nanofluid is used as the working media. The effects of Richardson number and outlet location as well as the volume fraction of the nanoparticles are addressed. In literature, mixed convection was also approached using two obstacles inside the enclosure. Karimi et al. (2016) simulated a mixed convection in a square cavity with two heated cylinders considering the effect of cylinder diameter and Richardson and Reynolds numbers. Whereas Khanafer et al. (2017) studied the mixed convection in a lid-driven cavity with two circular cylinders that positioned symmetrically. In a recent work, Khanafer et al. (2019) investigated the mixed convection in a differentially heated cavity with two rotating cylinders as well.

From the above, the following can be stated: Majority of the works on natural convection in cavities consider either closed cavities with heated cylinder or ventilated cavities with heat source placed at the walls. Moreover, open cavities with obstacles are only considered for mixed convection. To the best knowledge of the authors, the analyses of natural convection flow and heat transfer in partially opened enclosures with two isothermal hot circular cylinders have not been investigated. In this work, a numerical approach is presented for studying the natural convection heat transfer in a cavity with different opening configurations and confines two isothermal cylinders. Air is assumed to be the medium for heat transfer. To determine the best cooling scenarios, five different cavity configurations have been considered by changing the locations and sizes of the ventilation ports for Rayleigh number ranged between $10^{4}$ and $10^{6}$. At $\mathrm{Ra}=10^{6}$, for each configuration, the flow pattern and heat transfer characteristics are addressed for various horizontal distances between the cylinders as well as different vertical locations of the cylinders. As natural heat convection occurs without any external disturbances as fans or pumps, the best enclosure configuration under the above considered circumstances, is the one that can provide a higher heat transfer rate which is indicated by the average Nusselt number.

\section{MODEL CONFIGURATION AND GOVERNING EQUATIONS}

The schematic diagram of the physical system and the boundary conditions considered in this study along with the coordinate system are shown in Fig. 1. The considered system is a two-dimensional square enclosure with sides of length $L$. There are two hot circular cylinders with diameter $d$ (set to $0.2 L$ ) placed in the enclosure and separated by a distance $s$. The distance $s$ is varied from $0.1 \mathrm{~L}$ to $0.3 \mathrm{~L}$. The position of the cylinders $\left(y_{c}\right)$ is also assumed to vary along the vertical center line of the enclosure from $-0.2 L$ to $0.2 L$. Both cylinders are isothermal and have surface temperature of $T_{h}$. Cartesian coordinate system is utilized with the origin at the center of the enclosure. The side walls of the enclosure are kept adiabatic. The inflow openings are positioned at the bottom of the side walls whereas the out flow openings are located at the top. There are either a single opening with size of $0.2 L$ on one side wall or two openings each has a size of $0.1 L$ on two opposite side walls. The following assumptions are considered: The incoming fresh air is at the ambient temperature of $T_{\infty}$, the outgoing flow is extracted naturally and has zero diffusion flux for all variables, all solid boundaries of the cylinders and the enclosure are impermeable, and no-slip boundary conditions imposed on the walls where the velocities are set to zero. The hot cylinders heat the surrounding air in the cavity where the air starts moving up due to buoyancy effect toward the upper opening and leaves the enclosure. This motivates the atmospheric fresh air to enter the enclosure through the bottom openings. For this reason, the upper openings are indicated as outlets whereas the bottom ones are designated as inlets. According to the position and the size of the inlet and outlet openings, five configurations of the enclosure are considered as following: Configuration $\mathrm{A}$ where the openings are placed on the same side wall, configuration B where diagonal openings are assumed, configuration $\mathrm{C}$ where one inlet and two outlet openings are dedicated, configuration $\mathrm{D}$ has two inlet openings and one outlet, and finally in configuration $\mathrm{E}$ two inlets and two outlets are utilized. These configurations are shown in Fig. 2.

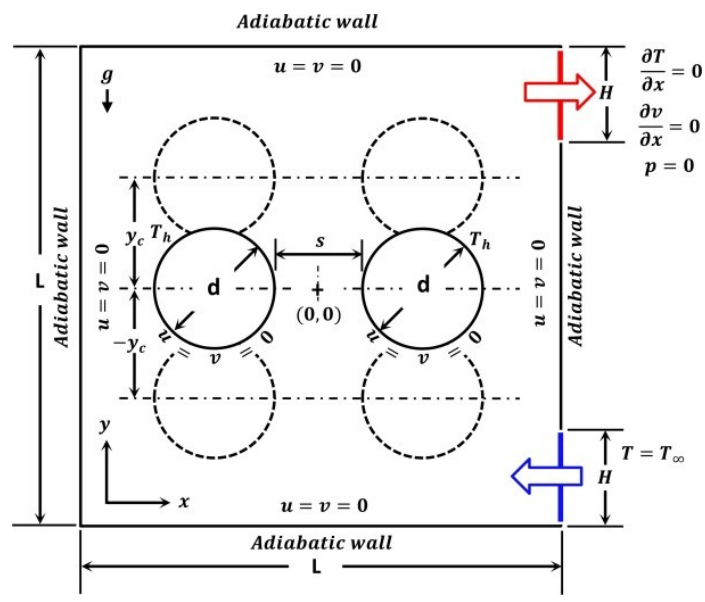

Fig. 1: Schematic description of the physical model along with boundary conditions

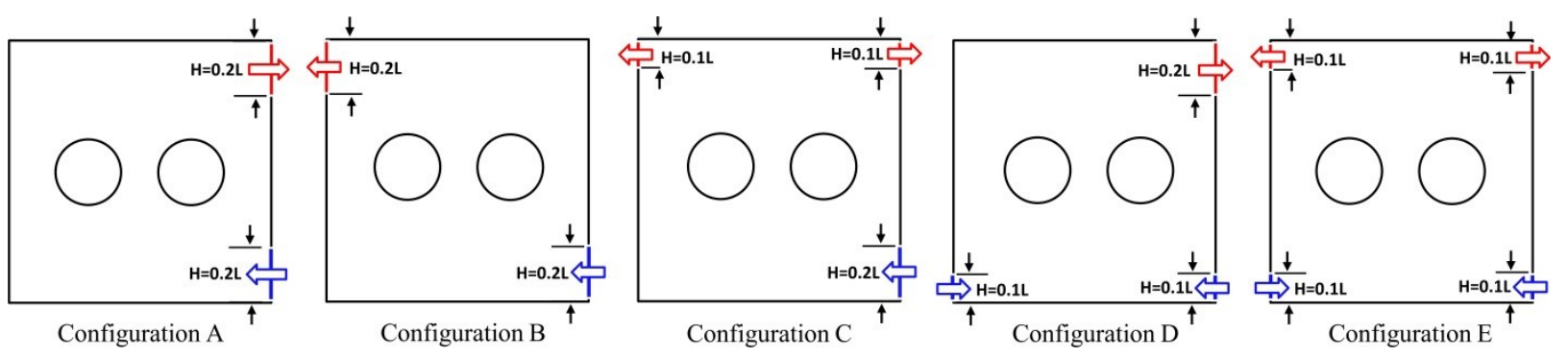

Fig. 2: Five configurations used in the study 
Natural convection heat transfer in any enclosure is based on the conservation equations of continuity, momentum and energy. The fluid is assumed to be Newtonian and it is also assumed that the flow within the enclosure is steady and two dimensional laminar flow. In addition, constant thermophysical fluid properties are assumed and Boussinesq approximation is adopted for density variation with temperature in the buoyancy term. The dimensionless form for conservation of mass, momentum and energy equations can be written as:

$\frac{\partial U}{\partial X}+\frac{\partial V}{\partial Y}=0$

$U \frac{\partial U}{\partial X}+V \frac{\partial U}{\partial Y}=-\frac{\partial P}{\partial X}+\operatorname{Pr}\left(\frac{\partial^{2} U}{\partial X^{2}}+\frac{\partial^{2} U}{\partial Y^{2}}\right)$

$U \frac{\partial V}{\partial X}+V \frac{\partial V}{\partial Y}=-\frac{\partial P}{\partial Y}+\operatorname{Pr}\left(\frac{\partial^{2} V}{\partial X^{2}}+\frac{\partial^{2} V}{\partial Y^{2}}\right)+\operatorname{RaPr} \theta$

$U \frac{\partial \theta}{\partial X}+V \frac{\partial \theta}{\partial Y}=\frac{\partial^{2} \theta}{\partial X^{2}}+\frac{\partial^{2} \theta}{\partial Y^{2}}$

where Pr and Ra are the Prandtl and Rayleigh numbers, respectively, which are given as:

$\operatorname{Pr}=\frac{v}{\alpha}, \quad R a=\frac{g \beta L^{3}\left(T_{h}-T_{\infty}\right)}{\alpha v}$

The dimensionless variables states in (1) through (4) are defined as:

$X=\frac{x}{L}, \quad Y=\frac{y}{L}, \quad U=\frac{u L}{\alpha}, \quad V=\frac{v L}{\alpha}, D=\frac{d}{L}, \quad S=\frac{s}{L}$,

$\delta=\frac{y_{c}}{L}, \quad P=\frac{p L^{2}}{\rho \alpha^{2}}, \quad \theta=\frac{T-T_{\infty}}{T_{h}-T_{\infty}}$

where $\mathrm{X}$ and $\mathrm{Y}$ are the coordinates along horizontal and vertical directions, $\mathrm{U}$ and $\mathrm{V}$ are velocity components in the directions of $\mathrm{X}$ and $\mathrm{Y}$, respectively, D is dimensionless diameter of the cylinders, $\mathrm{S}$ is the dimensionless distance between the two cylinders, $\delta$ is the dimensionless vertical location of the centerline of the cylinders, $\mathrm{P}$ is the dimensionless pressure, and $\theta$ is the dimensionless temperature.

The non-dimensional boundary conditions for the undertaken problem are:

1- On the solid surfaces of the cylinders as well as the enclosure, the velocities are: $\mathrm{U}=\mathrm{V}=0$ and the dimensionless temperature on the surfaces of the heated cylinders, $\theta=1$.

2- On the solid walls (not including the openings) of the enclosure:

$\partial \theta / \partial \mathrm{X}=0$ on the vertical walls and,

$\partial \theta / \partial \mathrm{Y}=0$ on the horizontal walls. And finally,

3- At the openings Gowda et al. (2019):

at the inlets: $\theta_{\text {in }}=0$ and,

at the outlets: $\partial \theta /\left.\partial \mathrm{X}\right|_{\text {out }}=0, \partial \mathrm{V} /\left.\partial \mathrm{X}\right|_{\text {out }}=0$ and $\mathrm{P}=0$.

To compare between the alternatives in heat exchange processes stated in section 1, the thermal system in this work is evaluated by the amount of rates in heat transfer. This is characterized by the local and average Nusselt number calculated at the surface of the heated cylinders. For the temperature distribution outcomes in the computational domain, the local Nusselt number can be computed from:

$N u=\frac{h d}{k}=-\frac{\partial \theta}{\partial n}$

where $\mathrm{h}, \mathrm{k}$ and $\mathrm{n}$ are the convection heat transfer coefficient, thermal conductivity of the fluid and the normal to the cylinder surfaces, respectively. Whereas the average Nusselt number is obtained by integrating the local Nusselt number over the surface of each cylinder. This can be calculated from:

$N u_{\text {avg }}=\frac{1}{2 \pi} \int_{0}^{2 \pi} \frac{\partial \theta}{\partial n} d \varphi$

where $\varphi$ is the angular position along the cylinder surface.

\section{SOLUTION METHODOLOGY AND VALIDATION}

The governing Eqs.(1) through (4) along with the boundary conditions have been solved using Galerkin weighted residual finite element method. Triangular elements are used to divide the computational domain illustrated in Fig. 1 considering all five configurations in Fig. 2. For the discretization of the pressure in the flow field, linear Lagrange elements are utilized. Whereas for the velocity, quadratic Lagrange elements are employed. Quadratic Lagrange elements are used in the discretization of the temperature in the energy equation as well. The solutions of the discretized equations are obtained by implementing damped Newton method. The convergence criteria is based on the accuracy of the domain variables which is set to $10^{6}$. To account for the high gradients in the velocities and temperatures, finer elements are used at the walls of the enclosure as well as at the cylinder surfaces.

To ensure the accuracy of the results, a grid sensitivity study is performed to obtain suitable grid distribution that can produce accurate results and minimize computational time. For that, seven different element numbers starts from around 1090 and ends at around 35500 are simulated for each configuration undertaken in this work. In all simulated cases, the following are considered $\mathrm{D}=0.2, \delta=0.0, \mathrm{~S}=0.2$, and $\operatorname{Pr}=0.71$. The values of the averaged Nusselt number on the cylinder surfaces $\left(\mathrm{Nu}_{\mathrm{avg}}\right)$ are computed for Rayleigh numbers of $10^{5}$ and $10^{6}$ and are shown in Fig. 3. It can be observed that up to around 21900 elements, the $\mathrm{Nu}_{\mathrm{avg}}$ changes with the variation in the elements numbers where they start settling down at constant values for each corresponding configuration when the number of the elements increases beyond 21900 elements. Therefore, element numbers between 22000 and 23000 elements depending on the undertaken configuration are considered for the rest simulations in this work.

In order to validate the computational procedure used in this work, three different problems from different references are simulated. The first problem imitates natural convection in a cold closed enclosure containing a hot circular cylinder presented in the works of Moukalled and Acharya (1996) and Shu and Zhu. (2002). The problem is simulated

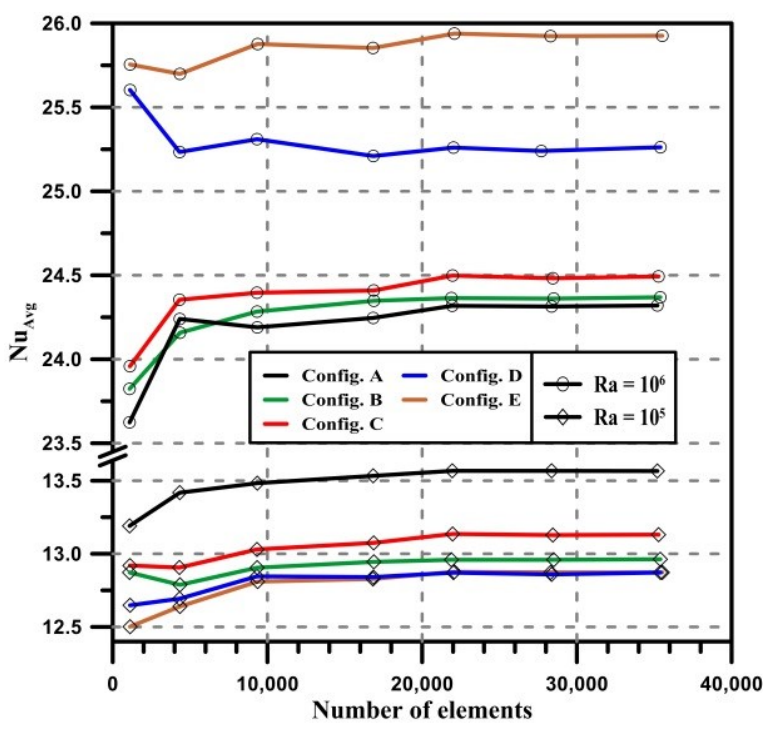

Fig. 3: Variation of average Nusselt number with number of elements 
Table 1: Comparison of surface averaged Nusselt number from present code with those presented in previous studies

\begin{tabular}{|c|c|c|c|c|c|c|c|c|c|}
\hline \multirow{2}{*}{$\mathrm{Ra}$} & \multicolumn{3}{|c|}{ Moukalled and Acharya (1996) } & \multicolumn{3}{c|}{ Shu and Zhu (2002) } & \multicolumn{3}{c|}{ This work } \\
\cline { 2 - 9 } & $\mathrm{D}=0.1$ & $\mathrm{D}=0.2$ & $\mathrm{D}=0.3$ & $\mathrm{D}=0.1$ & $\mathrm{D}=0.2$ & $\mathrm{D}=0.3$ & $\mathrm{D}=0.1$ & $\mathrm{D}=0.2$ & $\mathrm{D}=0.3$ \\
\hline $10^{4}$ & 2.071 & 3.331 & 5.826 & 2.082 & 3.245 & 5.395 & 2.069 & 3.225 & 5.371 \\
\hline $10^{5}$ & 3.825 & 5.080 & 6.212 & 3.786 & 4.861 & 6.214 & 3.777 & 4.908 & 6.212 \\
\hline $10^{6}$ & 6.107 & 9.374 & 11.620 & 6.106 & 8.898 & 12.000 & 6.108 & 8.897 & 11.948 \\
\hline
\end{tabular}
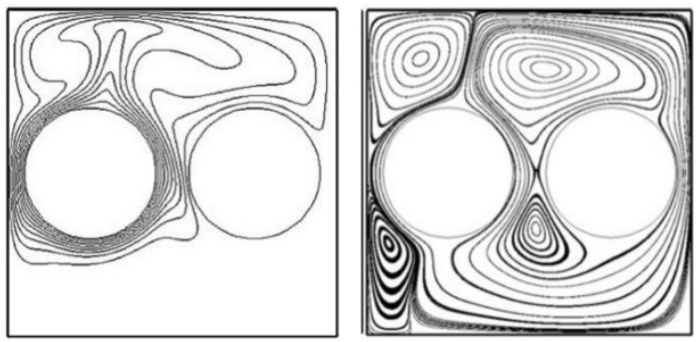

Park et al. (2012)
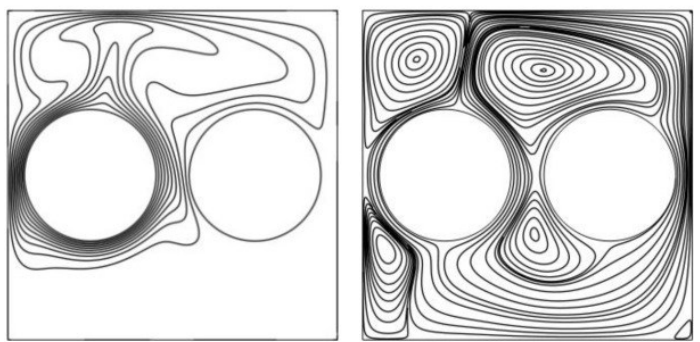

Present results

Fig. 4: Comparison of the streamlines (left) and isotherms (right) from the present results with that of Park et al. (2012).
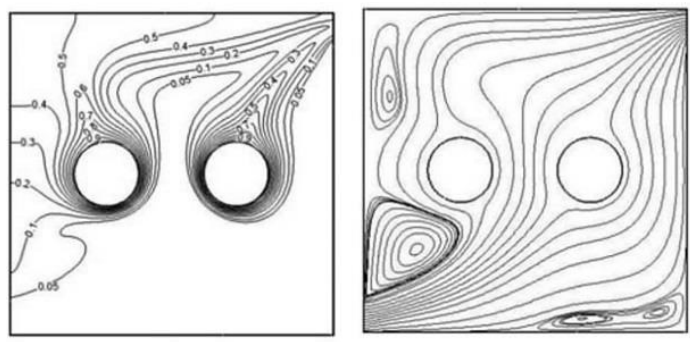

Karimi et al. (2014)
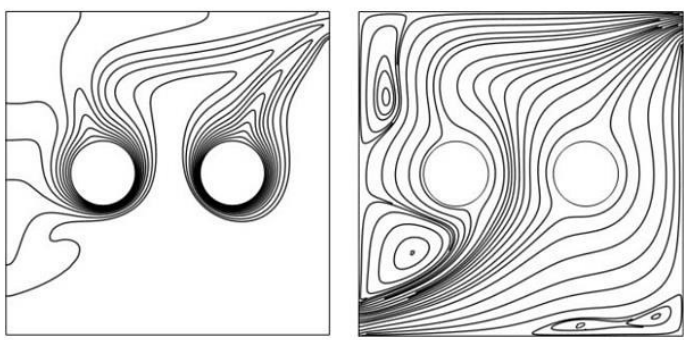

Present results

Fig. 5: Comparison of the streamlines (left) and isotherms (right) form the present results with that of Karimi et al. (2014).

for different diameters of the cylinder that change as $\mathrm{D}=0.1,0.2$ and 0.3 and for Rayleigh numbers that ranges from $10^{4}$ to $10^{6}$. The obtained values of the averaged Nusselt number at the cylinder surface according to the definition presented by Moukalled and Acharya (1996) are listed in table 1. As can be seen, the results show a close match with the values given in the study of Moukalled and Acharya (1996) and Shu and Zhu (2002). The second problem is presented by Park et al. (2012). The problem deals also with natural convection from hot and cold cylinders confined in a cold and closed enclosure. The results of the isotherms and streamline plots are compared for Rayleigh number of $10^{6}$ and presented in Fig. 4. A very close accordance can be observed between the two results. The final problem, however, mimics mixed convection in a square cavity that contains two isothermal hot cylinders with openings considered by Karimi et al. (2014). Once again, the outcomes, streamline and isotherms that obtained from the current work for the case of $\mathrm{D}=0.2, \mathrm{Ri}=1$, and $\mathrm{Re}=200$, are compared with the ones presented by Karimi et al. (2014) Fig. 5 illustrates the agreement between both results.

\section{RENAULTS AND DISCUSSION}

Recall that this work analyzes natural convections induced by two horizontal circular cylinders enclosed by square enclosure with openings. The cylinders are kept at constant hot temperatures while the enclosure walls are considered to be adiabatic. Five different configurations are conducted based on changes in the opening sizes and locations (Fig. 2) at Rayleigh number ranged from $10^{4}$ to $10^{6}$ where the cylinders are centered vertically $(\delta=0)$ and the dimensionless distance $(S)$ between them is set to 0.2 . In addition, for a constant Rayleigh number of $10^{6}$, the influence of different horizontal distances between the cylinders as well as vertical locations of the cylinders are also investigated for the considered configurations. The dimensionless distances $\mathrm{S}$ between the cylinders are varied from 0.1 to 0.3 whereas the dimensionless vertical locations $\delta$ are considered from -0.2 to 0.2 with increment of 0.1 for both variations. In all above cases, the dimensionless diameter of the cylinders are set to 0.2 whereas air is considered as the working fluid with Prantdl number (Pr) of 0.71. The followings discuss the main outcomes

\subsection{Effect of openings configurations and Rayleigh number}

Figs. 6 and 7 illustrate the effects of changing the size of the openings and their locations represented by configurations A through $\mathrm{E}$ as well as changes in Rayleigh number on the streamlines and temperature distributions. In Fig. 6, the columns from left to right show the streamline distribution for $\mathrm{Ra}$ of $10^{4}, 10^{5}$ and $10^{6}$, respectively, whereas the rows represent the considered configurations. Two observations can be built from the results as Ra increases. The first observation is the alternating domination of conduction and convection. While the second observation is the generation and development of vertices. Starting with $\mathrm{Ra}=10^{4}$, the streamlines in all configurations are smooth and the major flows are from the inlet to outlet openings with precursor for developing recirculation cells at the corner opposite to the outlet ports for configurations $\mathrm{A}, \mathrm{B}$ and $\mathrm{D}$ and inlet ports for configurations A, B and C. This could be because of poor buoyancy forces at low Rayleigh number which indicates that the heat transfer mechanism is dominated by conduction. As Rayleigh number increases to $10^{5}$, the natural convection appears more in the picture and starts to dominate the heat transfer mechanism which can be indicated by the distortion of the streamlines. As a result, the eddies in configurations A, through D become larger and more clear. Also new vortices are developing at the top of the inlet openings and under the inlet flow streams for all configurations. This is due to the expansion of the cold air as it enters the enclosure and its inability to accompanying the wall of the enclosure. Lastly with enhanced buoyancy when the Rayleigh number increases to $10^{6}$, the distortion of the streamlines increases 

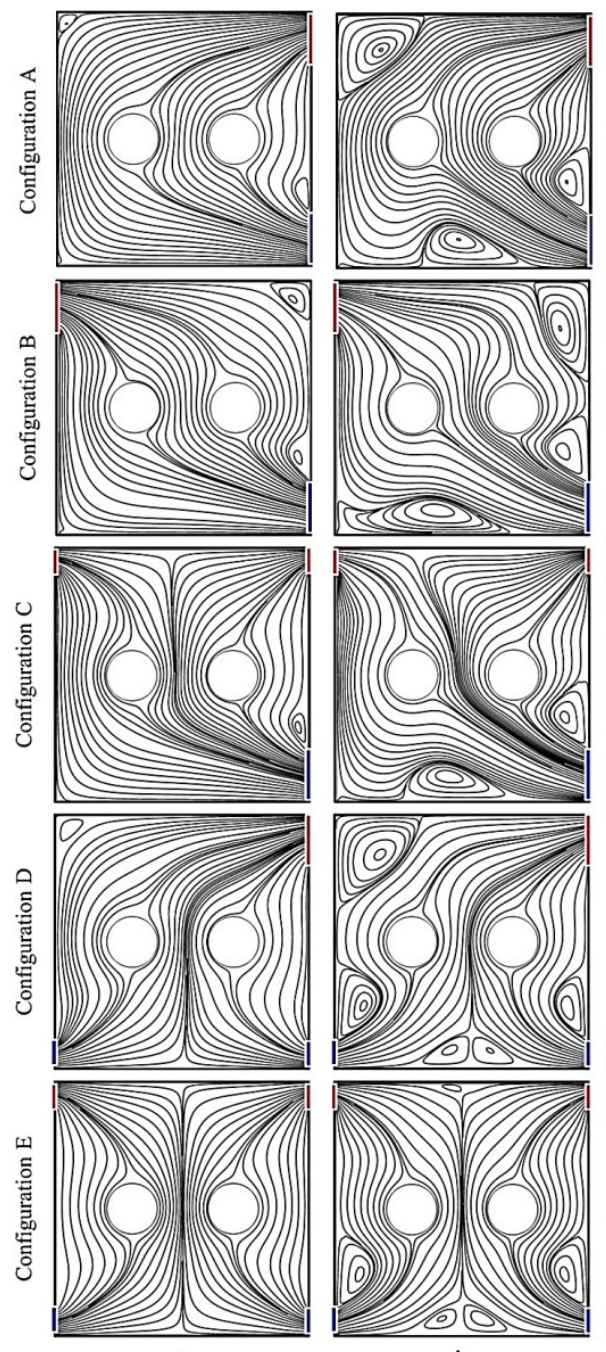
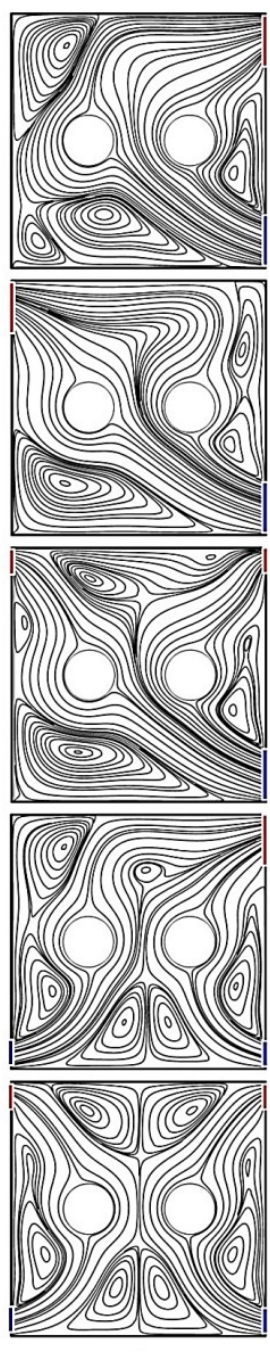

c
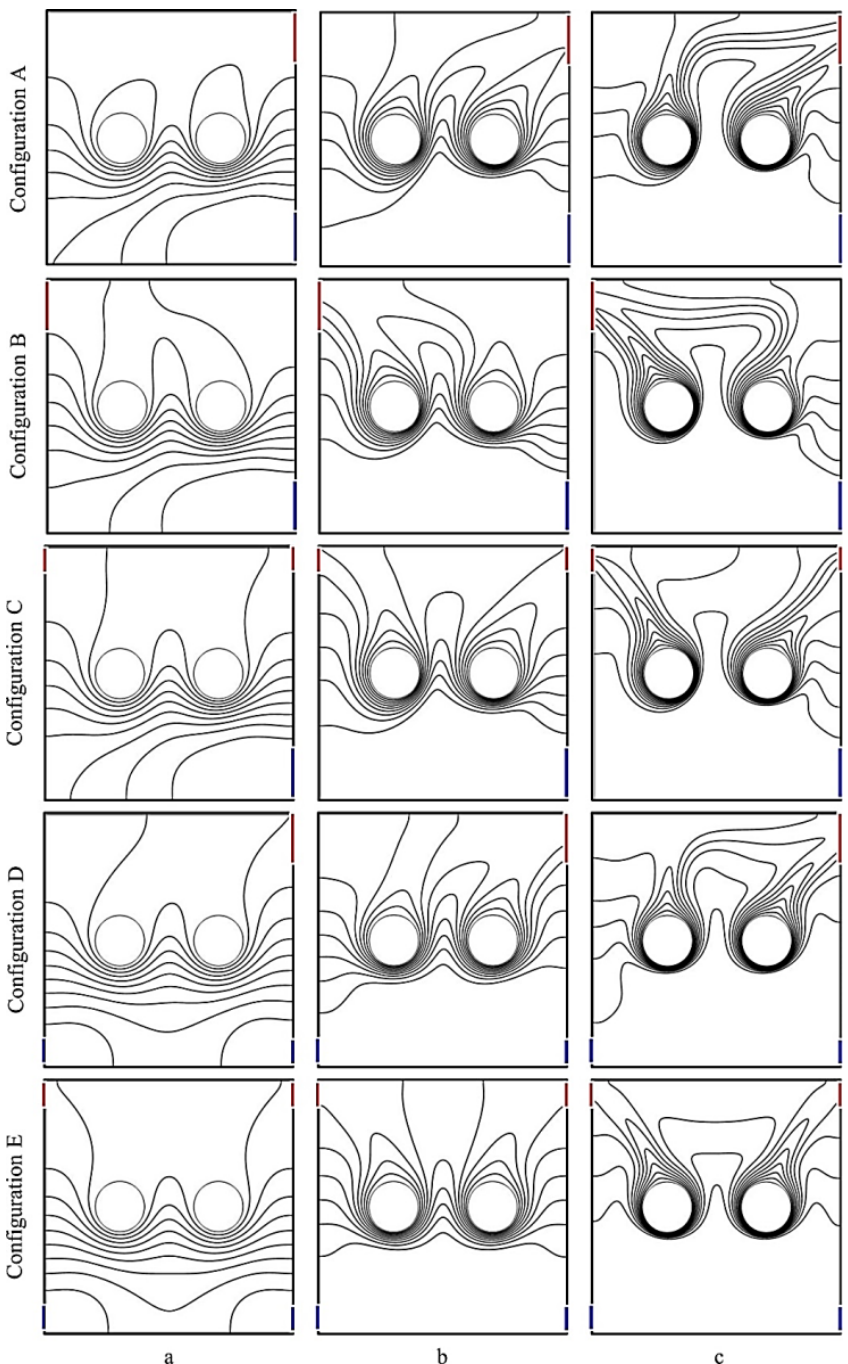

Fig. 7. Isotherms for all configurations at $\mathrm{S}=0.2$ and $\delta=0$, a) $\mathrm{Ra}=10^{4}$, b) $\mathrm{Ra}=10^{5}$ and c) $\mathrm{Ra}=10^{6}$

distortion can be seen in the isotherm contours and the convection effect becomes more evident in the plots. Consequently, thermal plumes start to construct around the cylinder upper surfaces directing toward the outlet in the all configurations. A uniform temperature distribution can be observed in the spaces between the cylinders and the vertical walls and between the cylinders as well. Moreover, a larger temperature gradient is observed around the cylinders especially in the region that is facing the inlet ports. For the zones under the cylinders, more cold air is occupying the zones near the inlets as the hot air is rising due to the increase in the convection actions. Finally, the convection effect becomes larger when the Rayleigh number is increased to $10^{6}$. The thermal plums above the cylinders become stronger and start rising toward the outlet openings. As a result, the buoyancy effects increase causing further fluid motion and sharper temperature gradients around the lower surfaces of the cylinders and hence enhance the heat transfer. For the configurations that have one outlet port (i.e. A, B and D), the thermal plums over the cylinders interact with each other and the path of the plumes that are far from the outlets are obstructed by the flows that are rising from the space between the cylinders. The rule of the cylinder that is far from the outlet is weakened in result. On the other hand, for the configurations with two outlets (i.e. $\mathrm{C}$ and $\mathrm{E}$ ), no interaction between the plumes is observed and the plumes above each cylinder move toward the nearest outlet. This fluid behavior and temperature distribution will reflect the role of each cylinder in the heat transfer 
process and can be clearly noted in the distribution of the local Nusselt number around the cylinders.

Local and average Nusselt numbers associated with changes in configurations verses $\mathrm{Ra}$ numbers are depicted by Figs. 8 and 9, respectively. In Fig. 8, the polar graphs of the local Nusselt number
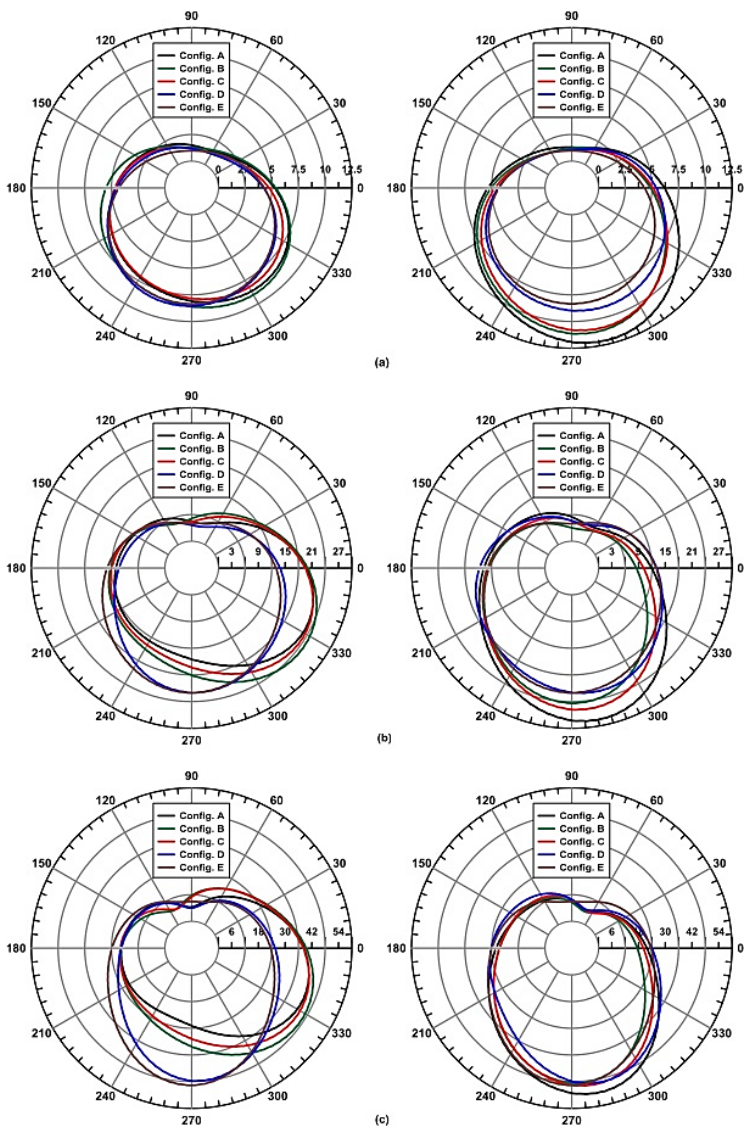

Fig. 8: Distribution of local Nu along the surface of left cylinder (left column) and right cylinder (right column) for all configurations at $\mathrm{S}=0.2$ and $\delta=0$, (a) $\mathrm{Ra}=10^{4}$, (b) $\mathrm{Ra}=10^{5}$ and (c) $\mathrm{Ra}=10^{6}$

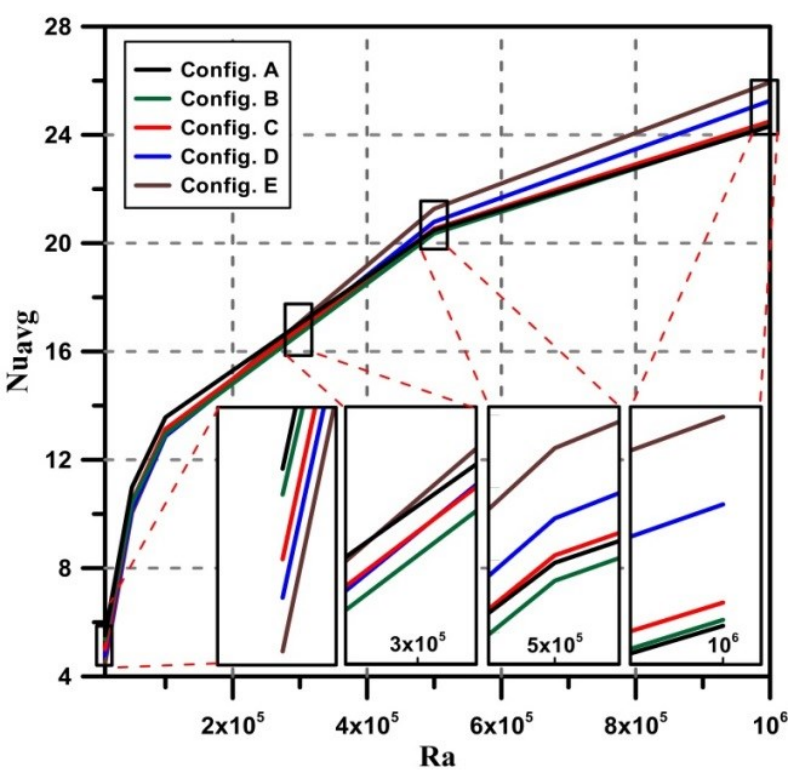

Fig. 9. Average Nusselt number of the cylinders as a function of Ra for all configurations at $\mathrm{S}=0.2$ and $\delta=0$ distributed along the cylinder surfaces for all configurations are plotted at Rayleigh numbers of $10^{4}, 10^{5}$, and $10^{6}$. Table 2 summaries the minimum and maximum values of the local $\mathrm{Nu}$ along with their corresponding angular positions. The left cylinder is represented in the left column while the right column is for right cylinder. At $\mathrm{Ra}=10^{4}$, as the conduction is dominating, the distribution of the local Nusselt numbers for all configurations on the left cylinders are almost similar as seen in Fig. 8a. However, some differences in the local Nusselt numbers can be observed in the lower part for the right cylinders where configuration $\mathrm{A}$ has the higher value of the local Nusselt number. In addition, configurations $\mathrm{B}$ and $\mathrm{C}$ have close Nusselt numbers that are higher than those of configurations $\mathrm{D}$ and $\mathrm{E}$ which also have close Nusselt numbers. Configurations A, B, and $\mathrm{C}$ have a peak value of the local Nusselt numbers at approximately $\varphi=300^{\circ}$ while the local Nusselt number has a peak at around $\varphi=270^{\circ}$ in configurations D and E. This is due to the high gradient in temperature distribution at these locations where configuration A has the largest gradient. This is obvious in Fig. 7. The variation of the local Nusselt numbers is ranging between 1.0 and 9.2 for the left cylinders whereas a range of 1.0 to 12.3 is noted for the right cylinders. The minimum value of local Nusselt number is observed for both cylinders at the location of minimum temperature gradients where thermal plumes are generated.

When Ra changes to $10^{5}$, as shown by Fig. $8 \mathrm{~b}$, the effect of the convection heat transfer increases, and this is reflected on the distribution of the local $\mathrm{Nu}$. For both cylinders, the minimum value of the local Nusselt number for all configurations appears at the top of the cylinders where the ascending plume is located at which the temperature gradient is the smallest. The minimum value is around 4.0 for both cylinders in all configurations except configuration B where the right cylinder shows a minimum of 2.9. For the left cylinder, the minimum happens at $\varphi$ that ranges between $80^{\circ}$ to $107^{\circ}$ whereas for the right cylinder this range drops by an average of $17^{\circ}$ as seen in table 2a. The local Nusselt number increases clockwisely along the surface of the left cylinder, where the temperature gradient increases as well, as noted in Fig. 7. Keeping with the left cylinder, the maximum value of the local $\mathrm{Nu}$ does not deviate from 23.32 that much for all configurations. The angular location of this maximum shows similar behavior where at configurations $\mathrm{A}, \mathrm{B}$ and $\mathrm{C}$ the peak occurs at around $\varphi=327^{\circ}$ whereas for $\mathrm{D}$ and $\mathrm{E}, \varphi$ is around $271^{\circ}$. Once again, these peak values correspond to the locations that are close to the inlet openings where temperature gradients are maximum at the cylinder surfaces. Geometrically, the angular locations of the maximum local Nusselt numbers can be related to the opening locations. On the left cylinders in configurations $\mathrm{A}, \mathrm{B}$, and $\mathrm{C}$, the inlets are positioned about $\varphi=330^{\circ}$. However, for $\mathrm{D}$ and $\mathrm{E}$ the maximum happens at $\varphi=270^{\circ}$ which is the mid-way between the two opposite inlets. On the other hand, for the right cylinders, the values of the maximum Nusselt numbers are different. Configuration A has the largest value of 28.9 whereas $\mathrm{D}$ and $\mathrm{E}$ have the lowest value of around 22. All maximums happen at close angles of around $\varphi=270^{\circ}$ to $281^{\circ}$. Lastly, for $\mathrm{Ra}=10^{6}$, the effect of the convection increases further which accordingly affects the value of the local Nusselt numbers. Interestingly, the geometry of $\mathrm{Nu}$ distribution is almost same as with $\mathrm{Ra}=10^{5}$. This can be seen in Fig. 8c. However, the numerical values of the minimum and maximum values are significantly different. For both cylinders, all configurations have almost same minimum of about 6.0. However, left cylinders reveal a maximum of about 46.0 while the right ones reach a maximum of about 50.0 except for configuration A where a maximum of 54.6 is observed.

It is important to state the following two points for all considered Ra. First, the configuration A has the largest local Nusselt number value at the right cylinder. The reason behind that is the position of the right cylinder which is located between the inlet and outlet openings. This makes the movement of the air to be higher around the cylinder and results in higher convection effects. Second, it can be noted that for configurations $\mathrm{B}$ and $\mathrm{C}$ along with $\mathrm{A}$, the cylinder that is closer to the outlet ports has more domination over heat transfer. This is because the 
Table 2a: Minimum values of local $\mathrm{Nu}$ and their angular locations for changes in $\mathrm{Ra}$ at $\mathrm{S}=0.2$ and $\delta=0$.

\begin{tabular}{|c|c|c|c|c|c|c|c|c|c|c|c|c|}
\hline \multirow{3}{*}{ Value of $\mathrm{Ra}$} & \multicolumn{6}{|c|}{ Minimum value of local $\mathrm{Nu}$} & \multicolumn{6}{|c|}{ Location of minimum value $\left(\varphi^{o}\right)$} \\
\hline & \multicolumn{3}{|c|}{ Left cylinder } & \multicolumn{3}{|c|}{ Right cylinder } & \multicolumn{3}{|c|}{ Left cylinder } & \multicolumn{3}{|c|}{ Right cylinder } \\
\hline & $10^{4}$ & $10^{5}$ & $10^{6}$ & $10^{4}$ & $10^{5}$ & $10^{6}$ & $10^{4}$ & $10^{5}$ & $10^{6}$ & $10^{4}$ & $10^{5}$ & $10^{6}$ \\
\hline Configuration $\mathrm{A}$ & 1.4 & 4.2 & 6.4 & 1.3 & 4.3 & 6.0 & 73.1 & 80.6 & 91.8 & 88.1 & 65.6 & 65.6 \\
\hline Configuration B & 1.3 & 4.5 & 6.7 & 1.2 & 2.9 & 5.4 & 88.1 & 106.8 & 114.3 & 99.3 & 80.6 & 69.3 \\
\hline Configuration $\mathrm{C}$ & 1.1 & 4.3 & 6.8 & 1.1 & 3.6 & 5.9 & 80.6 & 95.6 & 110.6 & 95.6 & 69.3 & 65.6 \\
\hline Configuration D & 1.1 & 3.4 & 6.0 & 1.1 & 4.2 & 6.5 & 73.1 & 80.6 & 91.8 & 95.6 & 76.8 & 69.3 \\
\hline Configuration $\mathrm{E}$ & 1.0 & 4.0 & 6.4 & 1.0 & 4.0 & 6.4 & 91.8 & 88.1 & 106.8 & 91.8 & 88.1 & 73.1 \\
\hline
\end{tabular}

Table 2b: Maximum values of local $\mathrm{Nu}$ and their angular locations for changes in Ra at $\mathrm{S}=0.2$ and $\delta=0$

\begin{tabular}{|c|c|c|c|c|c|c|c|c|c|c|c|c|}
\hline \multirow[b]{3}{*}{ Value of $\mathrm{Ra}$} & \multicolumn{6}{|c|}{ Maximum value of local $\mathrm{Nu}$} & \multicolumn{6}{|c|}{ Location of maximum value $\left(\varphi^{o}\right)$} \\
\hline & \multicolumn{3}{|c|}{ Left cylinder } & \multicolumn{3}{|c|}{ Right cylinder } & \multicolumn{3}{|c|}{ Left cylinder } & \multicolumn{3}{|c|}{ Right cylinder } \\
\hline & $10^{4}$ & $10^{5}$ & $10^{6}$ & $10^{4}$ & $10^{5}$ & $10^{6}$ & $10^{4}$ & $10^{5}$ & $10^{6}$ & $10^{4}$ & $10^{5}$ & $10^{6}$ \\
\hline Configuration A & 8.8 & 23.3 & 43.7 & 12.3 & 28.9 & 54.6 & 303.7 & 333.7 & 337.5 & 281.2 & 277.5 & 281.2 \\
\hline Configuration $\mathrm{B}$ & 9.2 & 25.1 & 47.5 & 11.3 & 24.6 & 49.2 & 300.0 & 322.5 & 326.2 & 277.5 & 270.0 & 273.7 \\
\hline Configuration $\mathrm{C}$ & 8.3 & 23.7 & 44.8 & 11.0 & 26.1 & 50.7 & 296.2 & 326.2 & 330.0 & 281.2 & 273.7 & 277.5 \\
\hline Configuration D & 8.7 & 22.2 & 48.3 & 9.1 & 22.5 & 50.1 & 266.2 & 273.7 & 273.7 & 281.2 & 281.2 & 285.0 \\
\hline Configuration E & 8.4 & 22.3 & 50.1 & 8.4 & 22.3 & 50.8 & 270.0 & 270.0 & 262.5 & 270.0 & 270.0 & 277.5 \\
\hline
\end{tabular}

fluid that is heated by that cylinder can leave faster as it has shorter path to the outlet. For the other two configurations, however, the two cylinders approximately have the same influence on the heat transfer as these configurations have two inlets or two outlets that lead to even distribution of the fluid among the cylinders.

To decide on the configuration that can produce a better natural convection, a comparison between the surface-averaged Nusselt numbers for all configurations at different Ra numbers is illustrated in Fig. 9. From this Fig., in general, it can be said that the average Nusselt number increases with the increase in the Rayleigh number for all configurations from about 5.0 at $\mathrm{Ra}=10^{4}$ to around five times more at $\mathrm{Ra}=10^{6}$. The increase in the average Nusselt number is due to the increase in the convection effects as Ra changes from $10^{4}$ to $10^{6}$. To simplify the comparison, two regions are assumed based on the Ra number. In the first region, Ra is considered to be less than $2.5 \times 10^{5}$. In the second region, where the convention mainly dominates the heat transfer rate, the $\mathrm{Ra}$ is greater than $2.5 \times 10^{5}$. In the first region, it is observed from Fig. 9 that configuration A gives the higher heat transfer rate while for the second region, the larger heat transfer rates are delivered by configuration $\mathrm{E}$ in the first place and configuration $\mathrm{D}$ in the second place. This indicates that at higher Ra number, the effects of the number of inlets and their relative locations with respect to the outlets are higher than that at lower Ra number. The effect of the location of the inlets and outlets on the heat transfer is limited through the guidance of the flow direction and path. This affects the role of each cylinder in the heat transfer mechanism as can be seen from the local Nusselt number distribution in Fig. 8. Thus, at low Ra, configuration A gives the higher heat transfer while configuration. E rules the heat transfer rate for higher Ra.

\subsection{Effect of variation in the horizontal distances between the cylinders}

To investigate the impact of the horizontal distances between the cylinders on the characteristic of the natural convection through the enclosure, a series of simulations are carried out where the dimensionless distances are varied from 0.1 to 0.3 . Not to forget that for $\mathrm{S}=0.2$, the simulations are already given in the previous section. The cylinders are placed at the centerline $(\delta=0)$ whereas the Ra is kept constant at $10^{6}$. In this series of simulations, the natural convection dominants the heat transfer rates which means that there is an energetic convection current that can affect the flow patterns and heat transfer characteristics mainly. The streamline and isotherm outcomes are shown in Figs. 10 and 11, respectively.

Fig. 10 shows the streamline distributions. In general, it can be observed from the plots that for small distance between the cylinders $(\mathrm{S}=0.1)$, the amount of the fluid that passes through the space between the vertical walls and the cylinders is larger than the amount of the fluid that passes in-between the two cylinders. On the other hand, when the distance increases, more fluid passes between the cylinders. As a result, the size and number of the circulation eddies formed inside the enclosure are essentially affected by the distance $\mathrm{S}$ for all configurations. For configuration $\mathrm{A}$, the size of the vortices above and below the left cylinder decreases with the increase in $\mathrm{S}$ and the small eddy in the lower left corner increases in size at $S=0.2$ and finally merges with the stream and shifts toward the lower portion of the left cylinder at $S=0.3$. Most impotently, the center of the upper vortex is also shifting toward the left vertical wall while the lower one is moving slightly toward the center line. As stated above, when the distance $S$ increases, the cylinders become closer to the vertical walls. In a result, the heated fluid by the cylinders rises toward the upper wall of the enclosure. This motivates more fluid in the stagnant region at the left upper corner to move and reduces the size of the vortices. The increase in $\mathrm{S}$ also narrows down the space between the right cylinder and the vertical wall which reduces the size of the corresponding eddy. A smooth air path between the inlet and outlet openings can be seen clearly for configuration B for all considered S. The lower vortex approximately keeps it size constant through all S despite some changes in its shape. As $S$ increases, the passing air between the cylinders along with the heated air by right cylinder occupy more space and squeeze down the eddy in the upper right corner of the enclosure. This causes a reduction in the size of the vortex as well. For configuration $\mathrm{C}$, similar behaviors can be realized regarding the vortices under the left cylinder as well as the one between the right cylinder and the vertical wall. As this configuration has two outlet ports, the heated fluid by each cylinder moves toward the nearest outlet. Consequently, the influence of the rising air on the region enclosed by the two cylinders and the upper wall becomes weaker as $\mathrm{S}$ increases. This leads to forming a circulation eddy where its size becomes larger with the increase in S. Interestingly, the increase in $S$ has no effect on the recirculation cell locations in the lower half of the enclosure in configurations D and E with slight effects on their sizes. This is related to the inlet structures for these two configurations. Having two inlets at the lower zone may distribute and guide the flow uniformly. Same with configuration A, the size of the vortex in the left upper corner in configuration D 
decreases with the increase in $\mathrm{S}$. As configuration $\mathrm{E}$ shares the same outlet structure with $\mathrm{C}$, in $\mathrm{S}=0.1$ similar results are obtained as in configuration $\mathrm{C}$. However, since configuration $\mathrm{E}$ has an extra inlet, two vortices are formed above the cylinders near the upper wall as $\mathrm{S}$ increases away from 0.1 . Differently from all other configurations, the flow pattern in configuration $\mathrm{E}$ is symmetric due to the symmetry in inlet and outlet distribution.

The contour of constant temperature lines in the Fig. 11 shows the effect of the variation in distances between the cylinders on the temperature filed in the enclosure. For all configurations, it is evident from the plots that the dimensionless distance $\mathrm{S}$ significantly affects the thermal plumes orientation and the temperature distributions around the cylinders. In addition, at $\mathrm{S}=0.1$, it is also observed that the upwelling plumes from the cylinders are mainly directing toward the exit ports. In the configurations that have one exit port (A, B and D), increasing in S allows more air to pass between the cylinders which enforces the plume over the cylinder far from the exit port to rise up then swerve to the exit port. In configurations with two outlets $(\mathrm{C}$ and $\mathrm{E})$, on the other hand, the plume over each cylinder is directed toward the nearest outlet regardless of the value of S. For all S, in configurations A, B and D, approximately uniform temperature distributions are noted in the region between the cylinders and the vertical walls opposite to the outlet due to weak air movement. Also uniform temperature distribution is noted in the space that conations both inlet and outlet between the cylinder and the vertical wall for configurations $\mathrm{C}$ and $\mathrm{E}$.
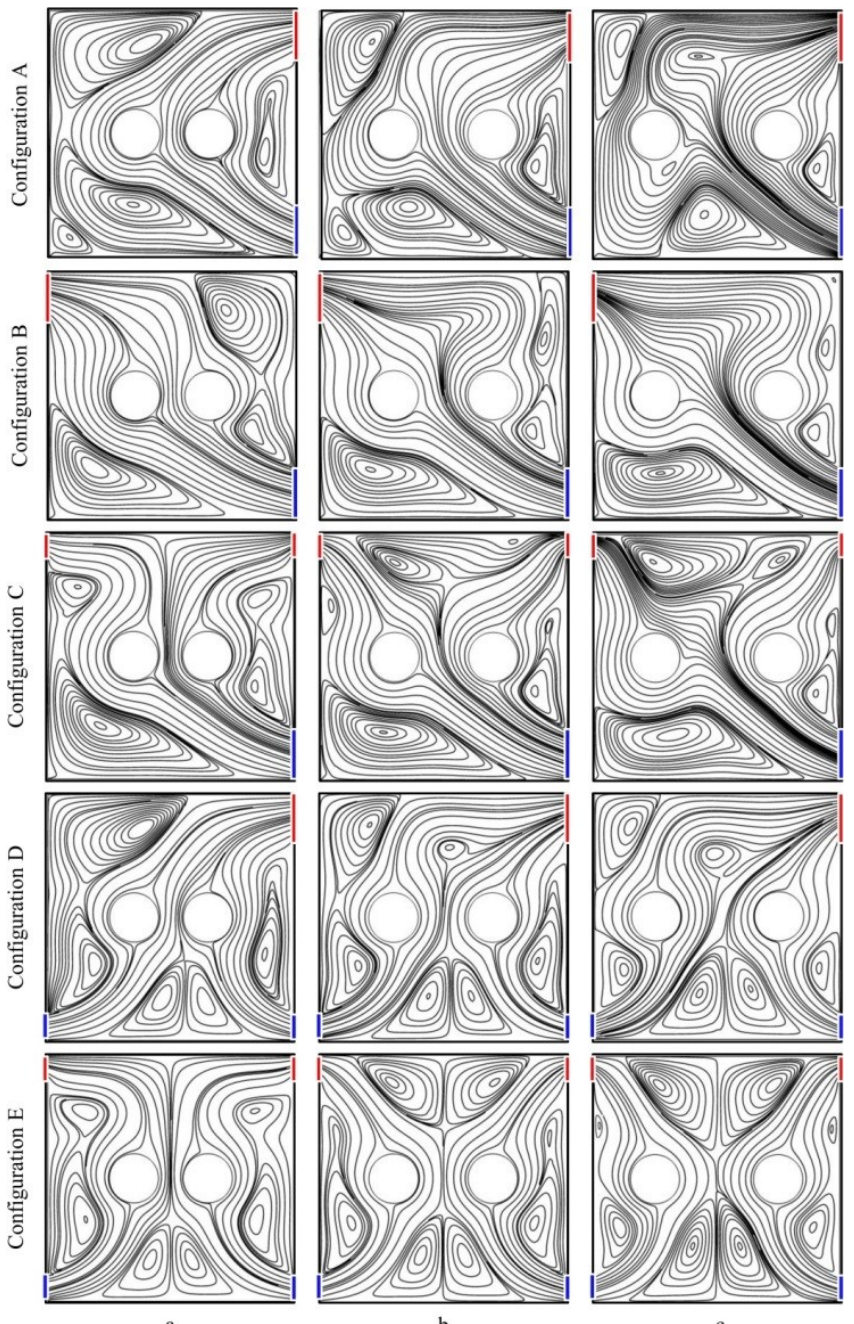

Fig. 10: Streamlines for all configurations for different value of the distance between the cylinders at $\delta=0$ and $\mathrm{Ra}=10^{6}$, (a) $\mathrm{S}=0.1$ (b) $\mathrm{S}=0.2$ and (c) $\mathrm{S}=0.3$
Approximately, for all configurations similar thermal behaviors are observed when $\mathrm{S}$ changes to 0.2 and 0.3 with differences being in the values. The only exception is that for configuration $\mathrm{A}$ at $\mathrm{S}=0.3$ some differences in temperature distribution behavior are noticed from that when $S=0.2$. This is because the inlet and outlet ports are located on same side of the vertical wall. At larger distance between the cylinders, more air passes between the cylinders toward the outlet which restricts the flow coming from the space between the left cylinder and the vertical wall as it can also be noted from Fig. 10. When the value of $S$ is 0.1 , the space between the cylinders is narrow where the air difficulty penetrates in between. This also causes the temperature lines to get closer with each other, and therefore, the temperature gradient increases. Another result for this is that more air moves through the zone between the cylinders and the vertical walls toward the outlets causing more heat to be dissipated. This justifies the longer path for the high temperatures gradient around the cylinders in compare with the cases when $\mathrm{S}$ is 0.2 or 0.3 which produces high rate in heat transfer as can be seen in Fig. 12.

Local Nusselt numbers around the cylinders for variation in $S$ are illustrated in Fig. 12. The solid line in the Fig. represents the baseline case where $\delta=0$ and $S=0.2$. The general observation from the Fig. is that the local Nusselt number distribution around the left cylinder in configurations $\mathrm{A}, \mathrm{B}$ and $\mathrm{C}$ is higher at $\mathrm{S}=0.1$ and decreases as $\mathrm{S}$ increases. In addition, for configurations $\mathrm{D}$ and $\mathrm{E}$, the distribution of the local $\mathrm{Nu}$ does not change that much on the left cylinder for all S. As
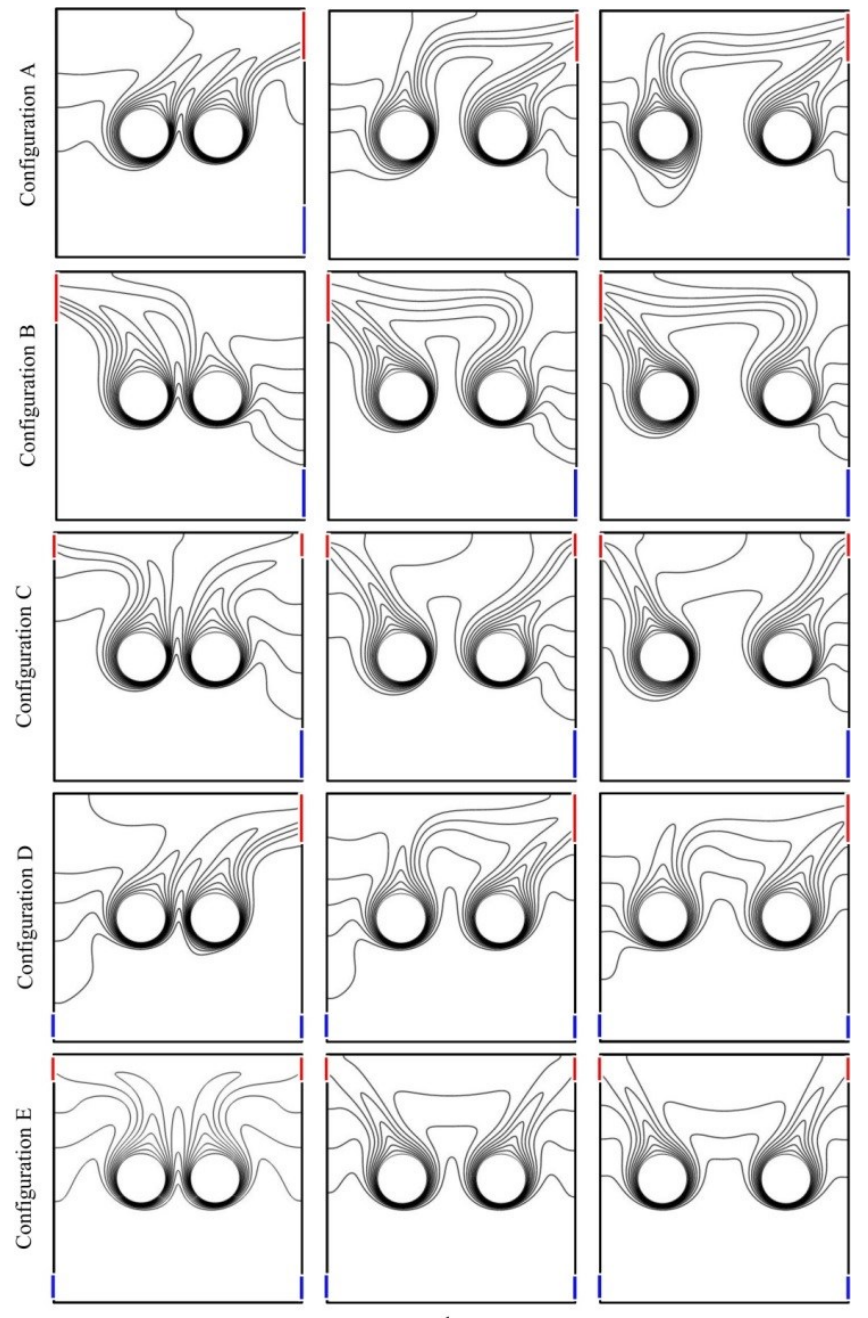

Fig. 11: Isotherms for all configurations for different value of the distance between the cylinders at $\delta=0$ and $\mathrm{Ra}=10^{6}$, (a) $\mathrm{S}=0.1$ (b) $\mathrm{S}=0.2$ and (c) $\mathrm{S}=0.3$ 
these two configurations have two inlets, the temperature distribution around the lower half of the left cylinder is mainly affected by the inflow stream that is guided by the inlet and outlet ports. Table 3 details the values and angular locations for the minimum and maximum of the local Nusselt numbers as S changes. For configuration A on the left cylinder, approximately a minimum value around 6.5 for the local Nusselt number is observed for all considered $\mathrm{S}$ whereas the maximum local Nusselt number is different. Around the right cylinder, the trend of the local $\mathrm{Nu}$ distribution shows insignificant changes with variation of $\mathrm{S}$ from 0.2 to 0.3 . But at $S=0.1$ a higher local Nusselt number is observed than other values of $\mathrm{S}$ in the angular position ranged from $60^{\circ}$
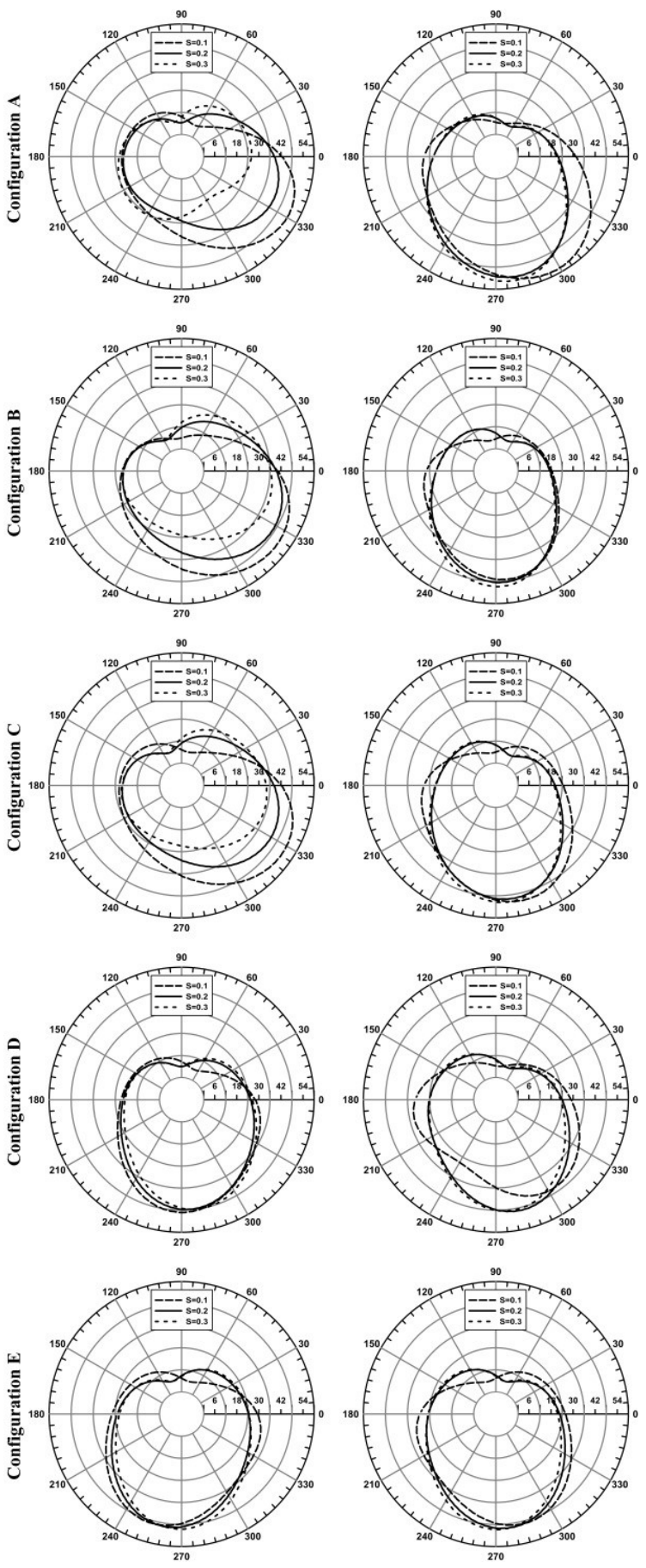

Fig. 12: Distribution of local $\mathrm{Nu}$ along the surface of left cylinder (left column) and right cylinder (right column) for all configurations at $\delta=0$ and $\mathrm{Ra}=10^{6}$ for different values of $\mathrm{S}$. to $280^{\circ}$ clockwise. This is due to higher temperature gradient in this angular range as it is noted in the isotherms plot in Fig. 11. The distribution of the local $\mathrm{Nu}$ around the left cylinder for configurations $\mathrm{B}$ and $\mathrm{C}$ roughly displays the same trends with slight deference in the positions of the minimum and maximum values. The Nusselt number increases gradually as moving down with clockwise direction until reaches the maximum values. The interesting point here is that the local Nusselt number distribution is higher for higher $\mathrm{S}$ in the range of $\varphi$ between $0^{\circ}$ and $110^{\circ}$ for $\mathrm{B}$ and between $15^{\circ}$ and the position of minimum value for $\mathrm{C}$. Outside this range, exactly the opposite status is noticed which is consistent with temperature gradient in Fig. 11. This is because the left cylinder obstructs the flow stream that is moving diagonally from the inlet to the outlet as $S$ increases, more fluid is passing between the cylinders and upper right quarter of the left cylinder. Thus, more heat transfers at this location between the hot cylinder surface and the cold fluid. The effect of increasing $\mathrm{S}$ from 0.2 to 0.3 on the local Nusselt number distribution around the right cylinder is trivial in configuration B and shares the same trajectories with $\mathrm{S}=0.1$ except that the locations of their minimum values are shifted anticlockwisly. Approximately same distribution of local $\mathrm{Nu}$ can be noticed with configuration $\mathrm{C}$. The only difference is that at $\mathrm{S}=0.1$ and in the range from the minimum to $280^{\circ}$ clockwise the values of local $\mathrm{Nu}$ are higher than those at $\mathrm{S}=0.2$ and 0.3 . This is due to the dense distribution of temperature in this location. On the right cylinder in configuration $\mathrm{D}$, the minimum value of the local Nusselt number occures in a narrow window for the angular position about $70^{\circ}$ for $\mathrm{S}=0.2$ and 0.3 . Changing the $\mathrm{S}$ from 0.2 to 0.3 has no effect on the local Nusselt number distribution. However, a complete different distribution is seen clearly for $S=0.1$. Lastly in configuration $E$, the local Nusselt number distributions are symmetric around the cylinders. This configuration has two inlets and two outlets which cause the flow stream to be distributed consistently among the cylinders. Hence, each cylinder participates evenly in the heat transfer process. For $S=0.2$ and 0.3 , the local Nusselt number distributions are the same while for $\mathrm{S}=0.1$ the whole distribution is shifted about $40^{\circ}$ clockwise on the left cylinder and counter clockwise on the right one.

Fig. 13 depicts the plot of the average Nusselt values which from the overall impact of varying the distance between the cylinders on the heat transfer behavior can be concluded. It is found that the heat transfer rate decreases sharply with the increase in the $S$ for configurations A, B, and C. However, the rate in the heat transfer nearly stays constant for configurations $\mathrm{D}$ and $\mathrm{E}$ especially after $\mathrm{S}=0.15$. The maximum value of the average Nusselt number is observed for configuration $\mathrm{A}$ at $\mathrm{S}=0.1$. While a minimum value is indicated for configuration B. A complete different result can be seen for $\mathrm{S} \geq 0.2$. Configurations $\mathrm{D}$ and $\mathrm{E}$ have higher heat transfer rates with higher value recorded for configuration $\mathrm{E}$ where the rates are almost constant at values of 25.2 and 26.0, respectively. While for the other configurations, the heat transfer decreases at least $10 \%$ in best scenario in compare with configuration $\mathrm{E}$ at $\mathrm{S}=0.3$. As it was reported in Fig. 12, because of the two inlet ports in configurations $\mathrm{D}$ and $\mathrm{E}$, both cylinders attain the same role in dominating the heat transfer for all $\mathrm{S}$ values in compare to other configurations where one of the cylinders plays this role. Thus, the variation in $S$ has a small effect on heat transfer rates in $\mathrm{D}$ and $\mathrm{E}$ for $\mathrm{S} \geq 0.15$ whereas in $\mathrm{D}$ the average $\mathrm{Nu}$ barley changes despite the changes in $\mathrm{S}$ with about 3\% less heat rate in compare with E.

\subsection{Effect of variation in cylinder vertical locations}

Behaviors of thermal and flow characteristics are also studied under the variation in the vertical locations $(\delta)$ of the cylinders where these locations are varied from $\delta=-0.2$ to 0.2 and both $\mathrm{Ra}$ and $\mathrm{S}$ are kept constant at $10^{6}$ and 0.2 , respectively. First and third columns from the left in Figs. 14 and 15 illustrate some of the outcomes for $\delta=-0.2$ and 0.2 , respectively. The case where the cylinders are positioned at the center of the enclosure $\delta=0.0$ is shown by the middle column. 
Table 3a: Minimum values of local $\mathrm{Nu}$ and their angular locations as the distance between cylinders $(\mathrm{S})$ changes $\left(\mathrm{Ra}=10^{6}\right)$.

\begin{tabular}{|c|c|c|c|c|c|c|c|c|c|c|c|c|}
\hline \multirow{3}{*}{ Value of S } & \multicolumn{6}{|c|}{ Minimum value of local $\mathrm{N}$} & \multicolumn{6}{|c|}{ Location of minimum value $\left(\varphi^{o}\right)$} \\
\hline & \multicolumn{3}{|c|}{ Left cylinder } & \multicolumn{3}{|c|}{ Right cylinder } & \multicolumn{3}{|c|}{ Left cylinder } & \multicolumn{3}{|c|}{ Right cylinder } \\
\hline & 0.1 & 0.2 & 0.3 & 0.1 & 0.2 & 0.3 & 0.1 & 0.2 & 0.3 & 0.1 & 0.2 & 0.3 \\
\hline Configuration $\mathrm{A}$ & 6.5 & 6.4 & 7.0 & 6.3 & 6.0 & 6.1 & 65.6 & 91.8 & 103.0 & 80.6 & 65.6 & 69.3 \\
\hline Configuration $\mathrm{B}$ & 5.7 & 6.7 & 7.1 & 4.7 & 5.4 & 5.4 & 95.6 & 114.3 & 118.1 & 99.3 & 69.3 & 69.3 \\
\hline Configuration $\mathrm{C}$ & 6.4 & 6.8 & 7.2 & 5.7 & 5.9 & 6.0 & 76.8 & 110.6 & 114.3 & 95.6 & 65.6 & 66.5 \\
\hline Configuration D & 5.7 & 6.0 & 6.1 & 6.2 & 6.5 & 6.5 & 65.6 & 91.8 & 91.8 & 84.3 & 69.3 & 73.1 \\
\hline Configuration $\mathrm{E}$ & 6.1 & 6.4 & 6.4 & 6.1 & 6.4 & 6.4 & 76.8 & 106.8 & 103.1 & 103.1 & 73.1 & 76.8 \\
\hline
\end{tabular}

Table 3b: Maximum values of local $\mathrm{Nu}$ and their angular locations as the distance between cylinders $(\mathrm{S})$ changes $\left(\mathrm{Ra}=10^{6}\right)$.

\begin{tabular}{|c|c|c|c|c|c|c|c|c|c|c|c|c|}
\hline \multirow[b]{3}{*}{ Value of S } & \multicolumn{6}{|c|}{ Maximum value of local $\mathrm{Nu}$} & \multicolumn{6}{|c|}{ Location of maximum value $\left(\varphi^{o}\right)$} \\
\hline & \multicolumn{3}{|c|}{ Left cylinder } & \multicolumn{3}{|c|}{ Right cylinder } & \multicolumn{3}{|c|}{ Left cylinder } & \multicolumn{3}{|c|}{ Right cylinder } \\
\hline & 0.1 & 0.2 & 0.3 & 0.1 & 0.2 & 0.3 & 0.1 & 0.2 & 0.3 & 0.1 & 0.2 & 0.3 \\
\hline Configuration A & 54.8 & 43.7 & 26.5 & 58.4 & 54.6 & 56.7 & 330.0 & 337.5 & 7.5 & 296.2 & 281.2 & 277.5 \\
\hline Configuration B & 54.1 & 47.5 & 38.6 & 47.7 & 49.2 & 51.3 & 318.7 & 326.2 & 341.2 & 277.5 & 273.7 & 270.0 \\
\hline Configuration $\mathrm{C}$ & 54.7 & 44.8 & 35.4 & 52.8 & 50.7 & 52.2 & 326.2 & 330.0 & 345.0 & 285.0 & 277.5 & 273.7 \\
\hline Configuration D & 49.7 & 48.3 & 48.6 & 46.0 & 50.1 & 49.4 & 270.0 & 273.7 & 281.2 & 303.7 & 285.0 & 277.5 \\
\hline Configuration E & 50.1 & 50.1 & 51.1 & 50.0 & 50.8 & 51.3 & 255.0 & 262.5 & 270.0 & 285.0 & 277.5 & 270.0 \\
\hline
\end{tabular}

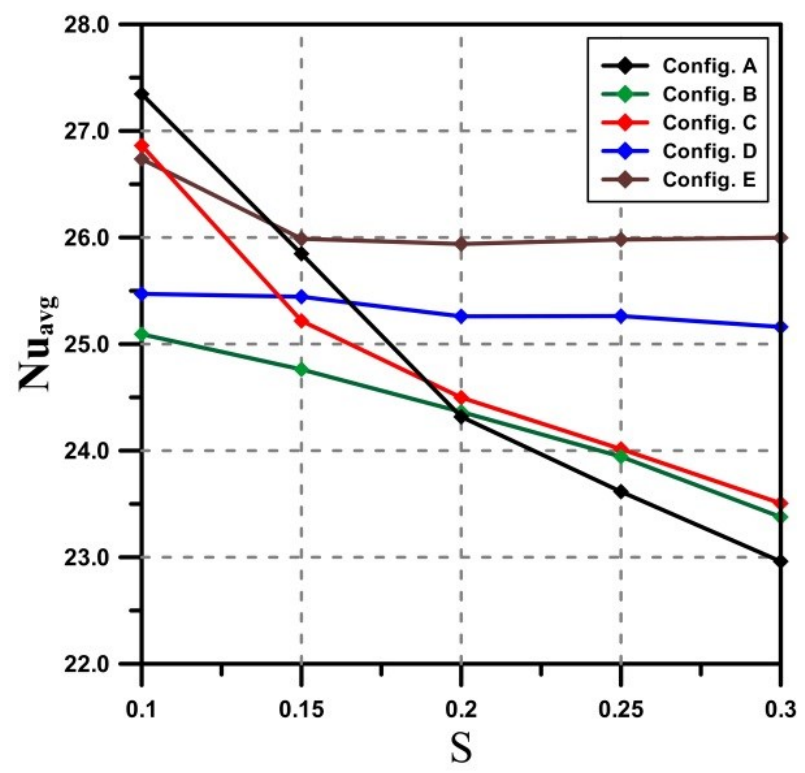

Fig. 13: Average Nusselt number of the cylinders as a function of (S) for all configurations at $\delta=0$ and $\mathrm{Ra}=10^{6}$

From the streamlines and isotherms shown by Figs. 14 and 15, it is clear that the vertical cylinder locations have significant effects on the velocity and temperature fields in the enclosure. Obviously, moving the cylinders up or down the cavity's horizontal center line will create more space in the opposite zone. Consequently, the cylinders reveal less obstruction to the flow for the case when $\delta=-0.2$ and the fluid flows more freely where the inlet and outlet ports configuration. the flow paths mainly. On the other hand, when $\delta=0.2$, the cylinders involve more in the fluid paths as they are closer to the outlet ports. For the followings, all explanations are in compare to the case where $\delta=0.0$. In Fig. 14, when the vertical location is at $\delta=-0.2$, the size of the vortices in the upper half of the enclosure in configurations $\mathrm{A}$ and $\mathrm{E}$ is larger. Whereas in configuration $\mathrm{B}$ the vortex in the right corner disappears and in $\mathrm{C}$ the vortex over the cylinders merges with the flow coming from the space between the cylinders. In configuration $\mathrm{D}$, the vortex in the upper left corner decreases in size while the one over the cylinders increases. It is also evident that in all configurations, the size of circulation eddies under the cylinders reduces considerably due to space limitation.
By moving the cylinders to $\delta=0.2$, in configuration $\mathrm{A}$ and because the inlet and outlet openings are on the same side wall, the heated air by the right cylinder obstructs the flow that tries to leave the enclosure. This enforces more air to retard and diffuse under the left cylinder which disturbs the flow stream. As a result, the two vortices under the left cylinder vanish. The size of vortices under the cylinders in configurations $\mathrm{B}$ through $\mathrm{E}$ increases, while the ones confined between the inlets in $\mathrm{D}$ and $\mathrm{E}$ get smaller as the vortices under the cylinders occupy more space. For the vortices above the cylinders, the cylinder locations do not affect their sizes that much in configurations $\mathrm{A}$ and D. For configuration B, however, as more fluid moves under the left cylinder toward the exit port, the circulation eddies in the upper right corner expand. Lastly in configuration $\mathrm{E}$, the vortices shrink in size due to space constraint.

As illustrated by the isotherms in Fig. 15 column (a), when the cylinders are at $\delta=-0.2$, they become closer to the inlets which consequently shorten the path for the fresh air to hit the hot cylinders. In addition, the large space over the cylinders gives the rising plumes the chance to move easily toward the outlets. Accordingly, the temperature gradients around the cylinders are denser in compare with other locations as can be seen by their effects on the local Nusselt numbers in Fig. 16. The temperature distributions for the cases $\delta=0.0$ and -0.2 are close in their patterns but with different numerical values. When the cylinders are located at $\delta=0.2$ (column c in Fig. 15), the plumes have a smaller zone above the cylinders which causes them to collide with the top wall and limits their sizes. This forces the plumes to incline toward the outlets of the enclosure and weakens the flow especially in the zone between the cylinders. And as a result, the temperature distributions between the cylinders become more uniform with smaller gradient which affects the heat transfer rate. All above outcomes are applied for all considered configurations.

The local Nusselt number distribution for changes in the vertical position of the cylinders is shown by Fig. 16. Table 4 shows the minimum and maximum local $\mathrm{Nu}$ values and the corresponding angular positions. The solid lines represent the baseline case where $\delta=0.0$. Except with the right cylinder in configuration A, the values of the local Nusselt numbers for both cylinders at $\delta=-0.2$ are larger than that of those when $\delta=0.0$ and 0.2 . For all configurations, as can be seen from table $4 \mathrm{a}$, the minimum values of the local $\mathrm{Nu}$ vary slightly between 4.2 to 6.8 . The corresponding angular locations for the minimums on the left cylinders occur at the angular zone $75.9^{\circ} \leq \varphi \leq$ $114.3^{\circ}$. Whereas on the right cylinders they occur at $50.6^{\circ} \leq \varphi \leq$ $103.1^{\circ}$. This can be interpreted as these zones represent the zones of low temperature gradients which correspond to the thermal plumes' 

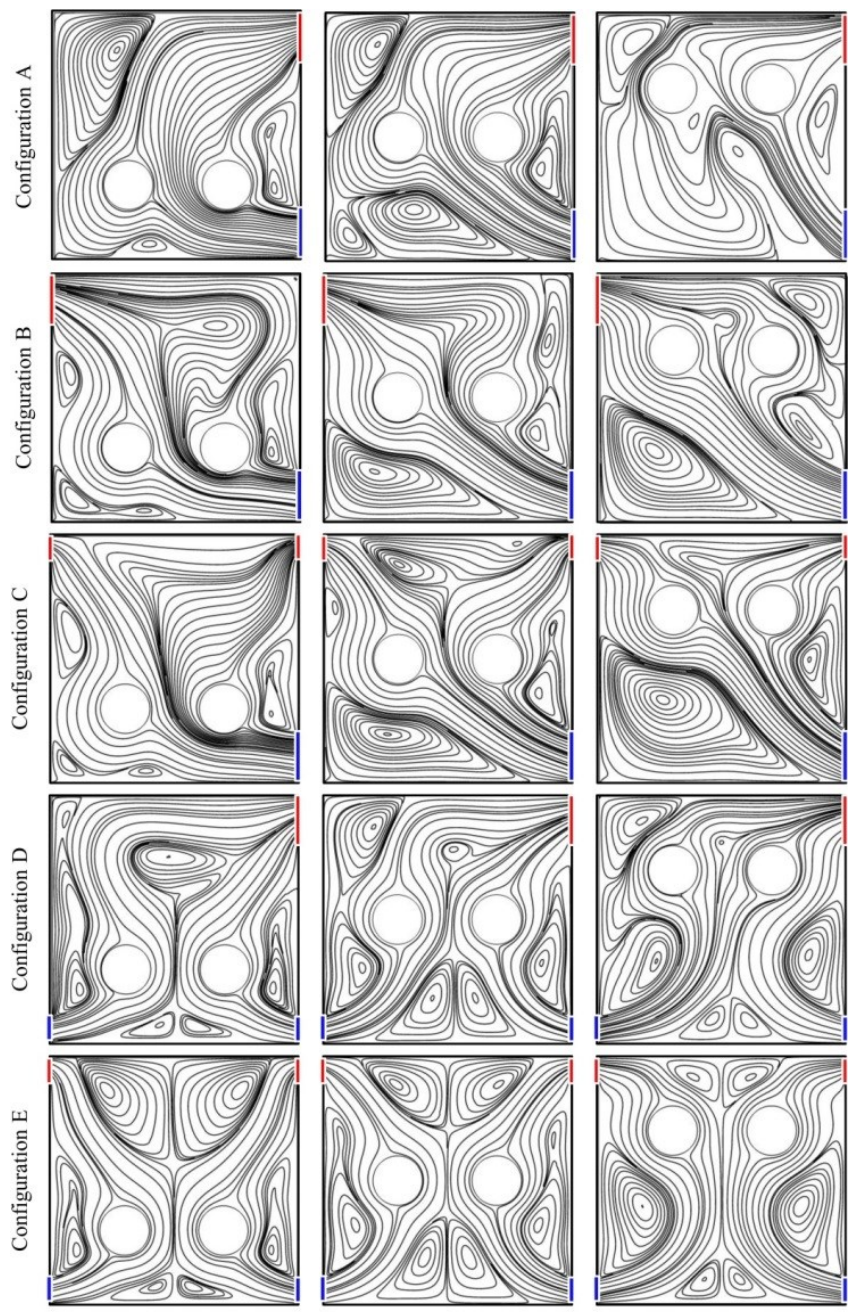

Fig. 14: Streamlines for all configurations for different value of the vertical location of the cylinders at $\mathrm{S}=0.2$ and $\mathrm{Ra}=10^{6}$, (a) $\delta=-0.2$ (b) $\delta=-0.0$ and (c) $\delta=0.2$.

locations and their directions toward the outlets. On the other hand, the maximum values depend mainly on the value of $\delta$ as illustrated by table $4 \mathrm{~b}$. The difference between the maximums is large and the peak values decrease as $\delta$ increases from -0.2 on all cylinders except the right cylinder in configuration A. Besides depending on $\delta$, the corresponding angular positions of the maximums are determined mainly by the locations of the inlets. The more the cylinders are moved toward the bottom of the enclosure, the more the angular positions direct toward the inlets. The reason for this phenomenon is that the entered fresh air faces the hot cylinders quicker as $\delta$ decreases. This causes a high difference in temperature which in result increases the convection heat transfer rate. This is shown in Fig. 16 where for configurations A, B, and $\mathrm{C}$, as $\delta$ decreases, the angular positions of the maximum values on the left cylinders are settling down at about $335^{\circ}$ which is facing the inlets. Same behavior can be witnessed for the right cylinders where the maximums turn counter clockwise towards $\varphi=315^{\circ}$. Similar observation can be drawn in configurations $\mathrm{D}$ and $\mathrm{E}$ where on the left cylinders the maximums approach the angle $240^{\circ}$ in clockwise and $303.7^{\circ}$ in counter clock wise for the right cylinders. This is because these configurations have two inlets on the opposite sides of the enclosure.

The following can be observed from the average Nusselt number shown by Fig. 17. In all configurations, the average $\mathrm{Nu}$ decreases as the cylinders move up from $\delta=-0.2$. This is because the temperature gradient around the cylinders decreases with the increase in $\delta$ as demonstrated by the distribution of local Nusselt numbers in Fig. 16.
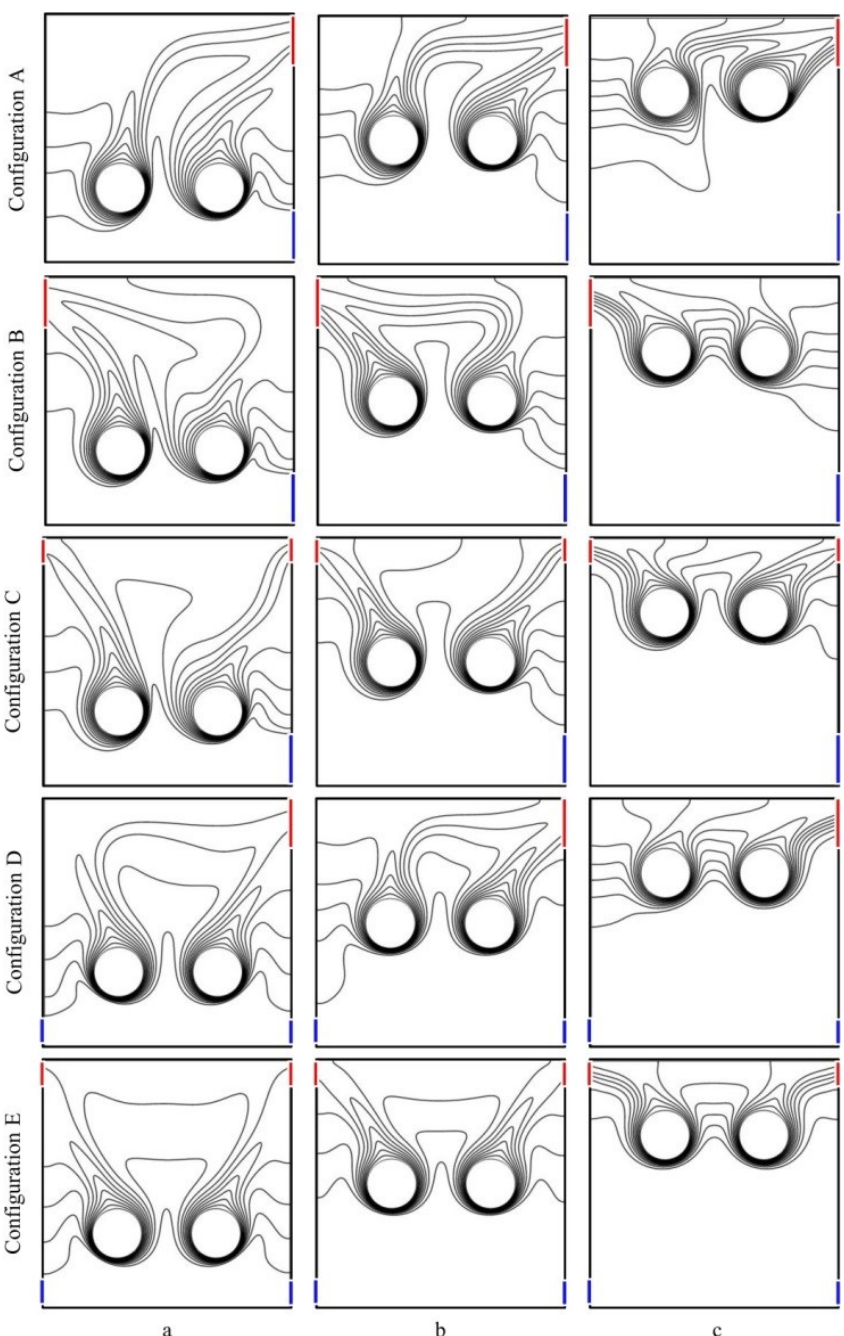

Fig. 15: Isotherms for all configurations for different value of the vertical location of the cylinders at $\mathrm{S}=0.2$ and $\mathrm{Ra}=10^{6}$, (a) $\delta=-0.2$ (b) $\delta=-0.0$ and (c) $\delta=0.2$.

The decay in configurations $\mathrm{A}$ and $\mathrm{C}$ is about $8 \%$ which is 3.29 times less than in configurations $\mathrm{B}$ and $\mathrm{E}$ where the reduction is about $26.3 \%$. Configuration $\mathrm{E}$ exhibits around $15.6 \%$ reduction in heat transfer rate. The influence of changing the vertical location of the cylinders on average $\mathrm{Nu}$ is limited in configurations $\mathrm{C}$ in the first place and $\mathrm{A}$ in the second place. While configurations $\mathrm{B}$ and $\mathrm{D}$ are sensitive to the changes in $\delta$. With holding all other variables constant, configuration $\mathrm{C}$ shows less sensitivity in changes in average $\mathrm{Nu}$ as $\delta$ is varied.

\section{CONCLUSIONS}

The current work addresses the behavior of natural convection in enclosures that have different openings and are excited by hot cylinders. The convection heat transfer is investigated for different changes through the cavity boundary. This includes different numbers of inlets and outlets with different sizes which form the five configurations A through E. These configurations are simulated for Rayleigh numbers (Ra) ranged from $10^{4}$ to $10^{6}$. In addition, variations in the horizontal distance between the cylinders as well as their vertical positions are considered too where the Rayleigh number is held constant at $10^{6}$. From the simulation of above scenarios, the following are concluded:

- At different Ra values, the location of the openings has an obvious impact on the heat transfer rates. At low Ra values, when the heat transfer mechanism is dominated by conduction, configurations with non-facing inlets or outlets have more heat transfer rates the opposite 

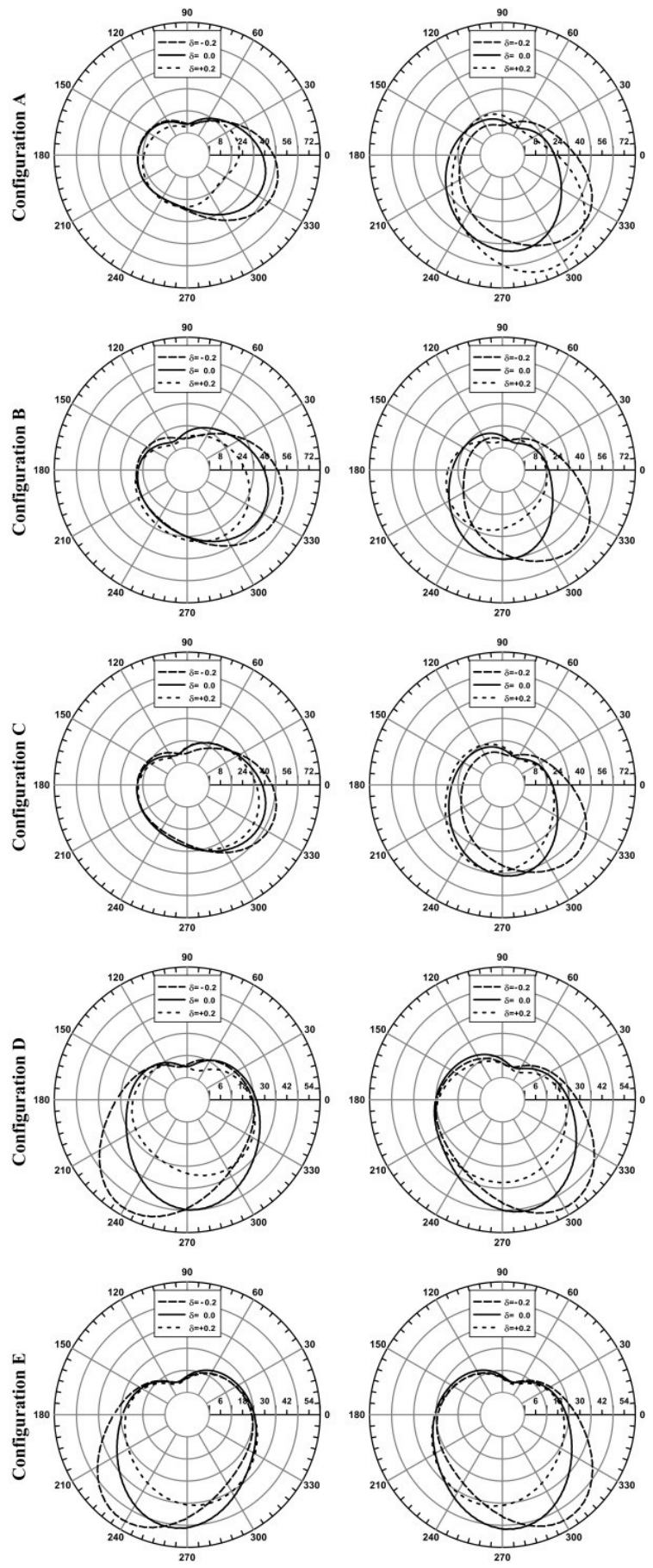

Fig. 16: Distribution of local Nu along the surface of left cylinder (left column) and right cylinder (right column) for all configurations at $\mathrm{S}=0.2$ and $\mathrm{Ra}=10^{6}$ for different value of $(\delta)$.

is true for high $\mathrm{Ra}$ values where the heat is mainly transferred by natural convection. Configurations with facing opening ports illustrate higher transfer rates. When $\mathrm{Ra}=10^{4}$, configuration $\mathrm{A}$ which has openings on same side-wall, shows the highest heat transfer rate. Followed by configurations B, C, D, and E. Configuration E, with lowest heat transfer rate, has two inlets and two outlets on opposite walls. In compare with E, configuration A dissipates $22.2 \%$ more heat. For $\mathrm{Ra}=10^{6}$, on the other hand, configuration E conducts the highest heat transfer rate where the order of heat rate dissipation is completely reversed. The increase of heat rate in $\mathrm{E}$ is about $7 \%$ in compare with configuration A which gives the lowest heat rate.

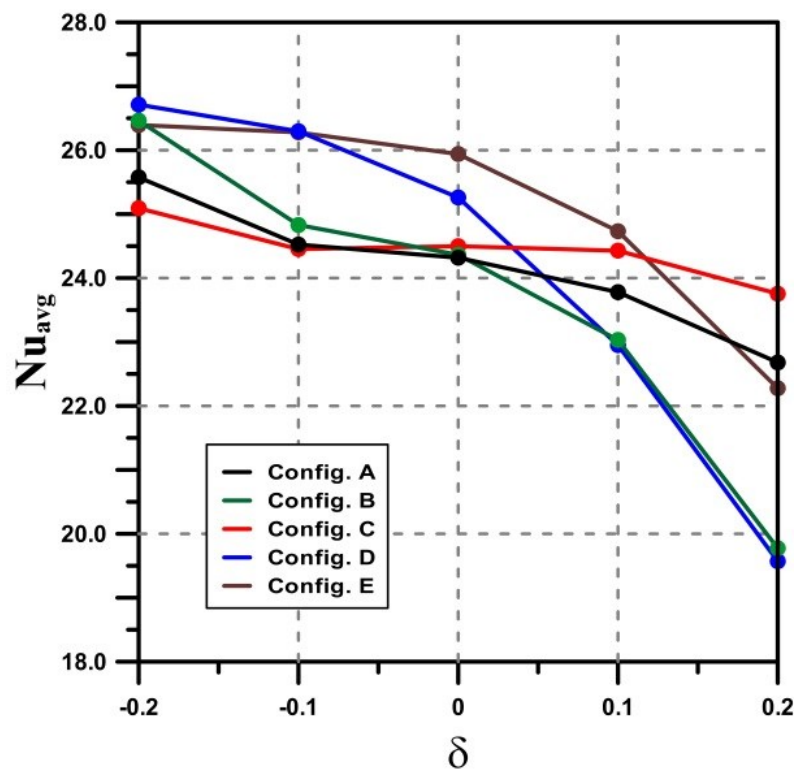

Fig. 17: Average $\mathrm{Nu}$ of the cylinders as a function of $(\delta)$ for all configurations at $\mathrm{S}=0.2$ and $\mathrm{Ra}=10^{6}$

- Also, the distribution of the openings affects the heat transfer rate from the hot cylinders as their in-between distances (S) change. Heat transfer in configurations with facing inlets on the side walls is almost not affected by the changes in the distances between the cylinders. This can be seen clearly with configurations D and E where the average Nusselt number $(\mathrm{Nu})$ nearly stays constant at about 25.3 and 26, respectively. Changes in S, however, cause configurations $\mathrm{A}$ through $\mathrm{C}$ to sharply decrease in the rate of heat being transferred. The average $\mathrm{Nu}$ drops by about $16 \%$ as $\mathrm{S}$ increases from 0.1 to 0.3 in configurations $\mathrm{A}$ and $\mathrm{C}$ and it does not get better in configuration $\mathrm{B}$.

- Once again, for variations in the vertical position of the cylinders, the inlet and outlet locations influence the heat transfer rates mainly. As the vertical positions of the cylinders $(\delta)$ vary, the heat transfer rate in configuration $\mathrm{C}$ barley changes where it drops only $5 \%$ as $\delta$ changes from -0.2 to 0.2 . Configuration $\mathrm{A}$ shows a similar behavior except it further drops in the average $\mathrm{Nu}$ by about $11.3 \%$. The heat transfer rate in configuration $\mathrm{B}$ illustrates akin changes in $\mathrm{A}$ and $\mathrm{C}$ up to $\delta=0$. However, the average $\mathrm{Nu}$ drops by $26.6 \%$ at $\delta=0.2$. This is the effect of the inlet and outlet architecture as configuration $\mathrm{C}$ combines the properties of both $\mathrm{A}$ and $\mathrm{B}$ where it has two openings at the same side-wall in addition to two diagonal openings. Configurations $\mathrm{D}$ and $\mathrm{E}$ conduct constant negative slope in the average $\mathrm{Nu}$ as $\delta$ increases. Yet, they dissipate more heat than other configurations with the leading of $\mathrm{E}$ up to $\delta=0.1$. This is due to the location of the two inlets in $\mathrm{D}$ and $\mathrm{E}$ and since $\mathrm{E}$ has two opposite outlets as with configuration $\mathrm{C}$, it can produce more rate in heat transfer in compare with other configurations up to $\delta=0.1$.

- A general observation: The average $\mathrm{Nu}$ for all configurations is inversely proportional to the changes in $\delta$. Same is true for configurations with one inlets with respect to changes in S.

- In overall, at high Ra when natural convection is completely dominating the heat transfer rate, configuration $\mathrm{E}$ illustrates better performance in dissipating heat despite the variations in $S$ and $\delta$. In addition, configurations $\mathrm{D}$ and $\mathrm{C}$ show insensitivity to changes in $\mathrm{S}$ and $\delta$, respectively. 
Table 4a: Minimum values of local $\mathrm{Nu}$ and their angular locations as the cylinder vertical location $(\delta)$ changes $\left(\mathrm{Ra}=10^{6}\right)$.

\begin{tabular}{|c|c|c|c|c|c|c|c|c|c|c|c|c|}
\hline \multirow[b]{3}{*}{ Value of $\delta$} & \multicolumn{6}{|c|}{ Minimum value of local $\mathrm{Nu}$} & \multicolumn{6}{|c|}{ Location of minimum value $\left(\varphi^{o}\right)$} \\
\hline & \multicolumn{3}{|c|}{ Left cylinder } & \multicolumn{3}{|c|}{ Right cylinder } & \multicolumn{3}{|c|}{ Left cylinder } & \multicolumn{3}{|c|}{ Right cylinder } \\
\hline & -0.2 & $\mathbf{0 . 0}$ & 0.2 & -0.2 & 0.0 & 0.2 & -0.2 & 0.0 & 0.2 & -0.2 & 0.0 & 0.2 \\
\hline Configuration A & 6.5 & 6.4 & 4.5 & 5.5 & 6.0 & 6.6 & 84.3 & 91.8 & 91.8 & 91.8 & 65.6 & 50.6 \\
\hline Configuration $\mathrm{B}$ & 6.7 & 6.7 & 4.8 & 5.5 & 5.4 & 4.2 & 95.6 & 114.3 & 114.3 & 84.3 & 69.3 & 103.1 \\
\hline Configuration $\mathrm{C}$ & 6.5 & 6.8 & 6.2 & 5.6 & 5.9 & 6.1 & 95.6 & 110.6 & 114.3 & 80.6 & 65.6 & 58.1 \\
\hline Configuration D & 6.1 & 6.0 & 4.5 & 6.3 & 6.5 & 4.8 & 99.3 & 91.8 & 75.9 & 76.8 & 69.3 & 65.6 \\
\hline Configuration E & 6.3 & 6.4 & 5.4 & 6.3 & 6.4 & 5.4 & 103.1 & 106.8 & 106.8 & 76.8 & 73.1 & 73.2 \\
\hline
\end{tabular}

Table 4b: Maximum values of local $\mathrm{Nu}$ and their angular locations as the cylinder vertical location $(\delta)$ changes $\left(\mathrm{Ra}=10^{6}\right)$.

\begin{tabular}{|c|c|c|c|c|c|c|c|c|c|c|c|c|}
\hline & \multicolumn{6}{|c|}{ Maximum value of local $\mathrm{Nu}$} & \multicolumn{6}{|c|}{ Location of maximum value $\left(\varphi^{\circ}\right)$} \\
\hline & \multicolumn{3}{|c|}{ Left cylinder } & \multicolumn{3}{|c|}{ Right cylinder } & \multicolumn{3}{|c|}{ Left cylinder } & \multicolumn{3}{|c|}{ Right cylinder } \\
\hline Value of $\delta$ & -0.2 & 0.0 & 0.2 & -0.2 & $\mathbf{0 . 0}$ & 0.2 & -0.2 & 0.0 & 0.2 & -0.2 & $\mathbf{0 . 0}$ & 0.2 \\
\hline Configuration $\mathrm{A}$ & 53.0 & 43.7 & 22.2 & 61.8 & 54.6 & 74.2 & 337.5 & 337.5 & 7.5 & 315.0 & 281.2 & 296.3 \\
\hline Configuration $\mathrm{B}$ & 57.7 & 47.5 & 38.8 & 61.8 & 49.2 & 30.1 & 333.7 & 326.2 & 300.0 & 315.0 & 273.7 & 236.2 \\
\hline Configuration $\mathrm{C}$ & 52.2 & 44.8 & 40.2 & 58.1 & 50.7 & 47.2 & 333.7 & 330.0 & 326.2 & 315.0 & 277.5 & 262.5 \\
\hline Configuration D & 56.6 & 48.3 & 31.8 & 56.3 & 50.1 & 33.2 & 240.0 & 273.7 & 303.7 & 303.7 & 285.0 & 270.0 \\
\hline Configuration $\mathrm{E}$ & 55.5 & 50.1 & 38.0 & 55.1 & 50.8 & 38.5 & 240.0 & 262.5 & 281.2 & 303.7 & 277.5 & 255.0 \\
\hline
\end{tabular}

\section{NOMENCLATURE}

d diameter of the cylinders

D dimensionless diameter of the cylinders

$g \quad$ acceleration due to gravity

$h \quad$ convection heat transfer coefficient

$H \quad$ opening height

$k \quad$ thermal conductivity

$L \quad$ side length of the enclosure

$n \quad$ direction normal to the surface

$\mathrm{Nu} \quad$ Nusselt number

$p \quad$ Pressure

$P \quad$ dimensionless pressure

$\mathrm{Pr} \quad$ Prandtl number

$R a \quad$ Rayleigh number

$s \quad$ distance between cylinders

$S \quad$ dimensionless distance between cylinders

$T \quad$ Temperature

$u, v \quad$ velocity components in $\mathrm{x}$ and y directions

$U, V \quad$ dimensionless velocity components in $\mathrm{x}$ and $\mathrm{y}$

$x, y \quad$ Cartesian coordinate

$X, Y \quad$ dimensionless Cartesian coordinate

Greek symbols

$\begin{array}{ll}\alpha & \text { thermal diffusivity } \\ \beta & \text { coefficient of thermal expansion } \\ \mu & \text { dynamic viscosity } \\ v & \text { kinematic viscosity } \\ \rho & \text { Density } \\ \theta & \text { dimensionless temperature } \\ \varphi & \text { angular position } \\ \delta & \text { dimensionless vertical location of the cylinders }\end{array}$

Subscripts

$H \quad$ hot surface

$\infty \quad$ Ambient

In Inlet

out Outlet

avg average

\section{REFERENCES}

Abdi, R. and Rezazadeh, N., 2016, "Numerical Simulation of Natural Convection from a Pair of Hot Cylinders in a Cold Square Enclosure in Different Boundary Conditions", Frontiers in Heat and Mass Transfer (FHMT), 7(1).

http://dx.doi.org/10.5098/hmt.7.30

Abhinav, R. et al., 2013, "Numerical Study on Effect of Vent Locations on Natural Convection in an Enclosure with an Internal Heat Source", International communications in heat and mass transfer, 49, 69-77. https://doi.org/10.1016/j.icheatmasstransfer.2013.09.001

Ali, M.H., 2008, "Numerical Study of Natural Convection from Two Parallel Horizontal Cylinders Enclosed by Circular Cylinder", Tikrit Journal of Engineering Science, 15(1), 51-69.

Bilgen, E. and Balkaya, A., 2008, "Natural Convection on Discrete Heaters in a Square Enclosure with Ventilation Ports", International journal of heat and fluid flow, 29(4), 1182-1189. https://doi.org/10.1016/j.ijheatfluidflow.2008.01.013

Bilgen, E. and Muftuoglu, A., 2008, "Natural Convection in an Open Square Cavity with Slots", International Communications in Heat and Mass Transfer, 35(8), 896-900.

https://doi.org/10.1016/i.icheatmasstransfer.2008.05.001

Boulahia, Z., Wakif, A. and Sehaqui, R., 2018, "Heat Transfer and CuWater Nanofluid Flow in a Ventilated Cavity Having Central Cooling Cylinder and Heated from the Below Considering Three Different Outlet Port Locations", Frontiers in Heat and Mass Transfer (FHMT), 11. http://dx.doi.org/10.5098/hmt.11.11

Chamkha, A.J., Hussain, S.H. and Abd-Amer, Q.R., 2011, "Mixed Convection Heat Transfer of Air inside a Square Vented Cavity with a Heated Horizontal Square Cylinder", Numerical Heat Transfer, Part A: Applications, 59(1), 58-79. https://doi.org/10.1080/10407782.2011.541216

Fontana, É., Da Silva, A. and Mariani, V.C., 2011, "Natural Convection in a Partially Open Square Cavity with Internal Heat Source: An Analysis of the Opening Mass Flow", International Journal of Heat and Mass Transfer, 54(7-8), 1369-1386.

https://doi.org/10.1016/j.ijheatmasstransfer.2010.11.053 
Gowda, B.K., Rajagopal, M. and Seetharamu, K., 2019, "Heat Transfer in a Side Heated Trapezoidal Cavity with Openings", Engineering Science and Technology, an International Journal, 22(1), 153-167. https://doi.org/10.1016/j.jestch.2018.04.017

Hussain, S.H. and Hussein, A.K., 2010, "Numerical Investigation of Natural Convection Phenomena in a Uniformly Heated Circular Cylinder Immersed in Square Enclosure Filled with Air at Different Vertical Locations", International Communications in Heat and Mass Transfer, 37(8), 1115-1126. https://doi.org/10.1016/j.icheatmasstransfer.2010.05.016

Karimi, F., Xu, H., Wang, Z., Yang, M. and Zhang, Y., 2016, "Numerical Simulation of Steady Mixed Convection around Two Heated Circular Cylinders in a Square Enclosure", Heat Transfer Engineering, 37(1), 64-75.

https://doi.org/10.1080/01457632.2015.1042343

Karimi, F., Xu, H.T., Wang, Z., Yang, M. and Zhang, Y., 2014, "Numerical Simulation of Unsteady Natural Convection from Heated Horizontal Circular Cylinders in a Square Enclosure", Numerical Heat Transfer, Part A: Applications, 65(8), 715-731.

https://doi.org/10.1080/10407782.2013.846607

Khanafer, K., Aithal, S. and Vafai, K., 2019, "Mixed Convection Heat Transfer in a Differentially Heated Cavity with Two Rotating Cylinders", International Journal of Thermal Sciences, 135, 117-132. https://doi.org/10.1016/j.ijthermalsci.2018.07.020

Khanafer, K., Aithal, S., Assad, M.E. and Pop, I., 2017, "Flow and Heat Transfer in a Driven Cavity with Two Cylinders", Journal of Thermophysics and Heat Transfer, 31(1), 99-108.

https://doi.org/10.2514/1.T4744

Kim, M., Doo, J.H., Park, Y.G., Yoon, H.S. and Ha, M.Y., 2014, "Natural Convection in a Square Enclosure with a Circular Cylinder According to the Bottom Wall Temperature Variation", Journal of Mechanical Science and Technology, 28(12), 5013-5025.

https://doi.org/10.1007/s12206-014-1123-1

Mamun, M., Rahman, M., Billah, M. and Saidur, R., 2010, "A Numerical Study on the Effect of a Heated Hollow Cylinder on Mixed Convection in a Ventilated Cavity", International Communications in Heat and Mass Transfer, 37(9), 1326-1334.

https://doi.org/10.1016/j.icheatmasstransfer.2010.07.019

Mariani, V.C. and Silva, A.d., 2007, "Natural Convection: Analysis of Partially Open Enclosures with an Internal Heated Source", Numerical Heat Transfer, Part A: Applications, 52(7), 595-619. https://doi.org/10.1080/10407780701338423

Moukalled, F. and Acharya, S., 1996, "Natural Convection in the Annulus between Concentric Horizontal Circular and Square Cylinders", Journal of Thermophysics and Heat Transfer, 10(3), 524531. https://doi.org/10.2514/3.820

Park, J., Kim, M., Mun, G.S., Park, Y.G. and Ha, M.Y., 2018, "Natural Convection in a Square Enclosure with a Circular Cylinder with
Adiabatic Side Walls According to Bottom Wall Temperature Variation", Journal of Mechanical Science and Technology, 32(7), 3201-3211.

https://doi.org/10.1007/s12206-018-0623-9

Park, Y.G., Yoon, H.S. and Ha, M.Y., 2012, "Natural Convection in Square Enclosure with Hot and Cold Cylinders at Different Vertical Locations", International Journal of Heat and Mass Transfer, 55(2526), 7911-7925.

https://doi.org/10.1016/j.ijheatmasstransfer.2012.08.012

Rahman, M., Alim, M., Saha, S. and Chowdhury, M., 2008a, "Mixed Convection in a Vented Square Cavity with a Heat Conducting Horizontal Solid Circular Cylinder", Journal of naval architecture and marine engineering, 5(2), 37-46.

https://doi.org/10.3329/jname.v5i2.2504

Rahman, M.M., Alim, M.A., Saha, S. and Chowdhury, M., 2008b, "A Numerical Study of Mixed Convection in a Square Cavity with a Heat Conducting Square Cylinder at Different Locations", Journal of Mechanical Engineering, 39(2), 78-85.

https://doi.org/10.3329/jme.v39i2.1850

Rahman, M.M., Parvin, S., Hasanuzzaman, M., Saidur, R. and Rahim, N.A., 2013, "Effect of Heat-Generating Solid Body on Mixed Convection Flow in a Ventilated Cavity", Heat transfer engineering, 34(15), 1249-1261.

https://doi.org/10.1080/01457632.2013.730919

Roychowdhury, D., Das, S.K. and Sundararajan, T., 2002, "Numerical Simulation of Natural Convective Heat Transfer and Fluid Flow around a Heated Cylinder inside an Enclosure", Heat and mass transfer, 38(78), 565-576.

https://doi.org/10.1007/s002310100210

Shu, C. and Zhu, Y., 2002, "Efficient Computation of Natural Convection in a Concentric Annulus between an Outer Square Cylinder and an Inner Circular Cylinder", International journal for numerical methods in fluids, 38(5), 429-445.

https://doi.org/10.1002/fld.226

Shuja, S., Yilbas, B. and Iqbal, M., 2000, "Mixed Convection in a Square Cavity Due to Heat Generating Rectangular Body", International Journal of Numerical Methods for Heat \& Fluid Flow. https://doi.org/10.1108/09615530010359120

Yoon, H.S., Jung, J.H. and Park, Y.G., 2012, "Natural Convection in a Square Enclosure with Two Horizontal Cylinders", Numerical Heat Transfer, Part A: Applications, 62(9), 701-721. https://doi.org/10.1080/10407782.2012.709438

Yoon, H.S., Park, Y.G. and Jung, J.H., 2014, "Natural Convection in a Square Enclosure with Differentially Heated Two Horizontal Cylinders", Numerical Heat Transfer, Part A: Applications, 65(4), 302326.

https://doi.org/10.1080/10407782.2013.831679 